\title{
Sahilkent (Bafra, Samsun) yöresindeki alüvyal zeminlerin sıvılaşma potansiyelinin CPT verileri kullanılarak araştırılması
}

\author{
Investigating liquefaction potential of alluvial soils in Sahilkent (Bafra, Samsun) area using \\ CPT data
}

\author{
Muhammet Oğuz SÜNNETCI*1,a, Hakan ERSOY ${ }^{1, b}$ \\ ${ }^{1}$ Karadeniz Teknik Üniversitesi, Mühendislik Fakültesi, Jeoloji Mühendisliği Bölümü, 61080, Trabzon
}

• Geliş tarihi / Received: 17.10.2020 • • Düzeltilerek geliş tarihi / Received in revised form: 31.12.2020 • Kabul tarihi / Accepted: 15.01.2021

\begin{abstract}
Öz
Bu çalışmada Sahilkent (Bafra, Samsun) yöresindeki kil, silt ve kum boyutlu malzemelerden oluşan alüvyal zeminlerin sıvılaşma potansiyeli CPT verileri kullanılarak araştırılmıştır. Çalışma kapsamında Bafra ilçesi genelinde her biri 15 metre derinliğinde 20 adet sondaj yapılmış, bunlardan Sahilkent yöresindeki 5 tanesinden UD tip örnek alıcılarla her 1 metrede 1 adet olacak şekilde örselenmemiş zemin örnekleri temin edilmiştir. Bu örneklerden silt ve kum oranı yüksek olan 20 tanesi üzerinde sslak elek, hidrometre, plastik limit, likit limit ve doğal su muhtevası tayinleri yapılmıştır. Yapılan ön değerlendirmede farklı derinliklerdeki bazı bölgelerde sıvılaşma potansiyelinin olduğu belirlenmiş ve detaylı sıvılaşma analizlerin yapılabilmesi amacıyla 5 sondaj kuyusunun 1'er metre yakınında 15 'er metrelik CPTu deneyi uygulanmıştır. $\mathrm{CPTu}$ deneylerinde koni uç direnci, kenar sürtünmesi, efektif gerilme, rölatif sıkılık vb. veriler her $5 \mathrm{~cm}$ 'de bir kaydedilmiş, sıvılaşma analizlerinde bu verilerin her 1 metre derinlik için ortalamaları alınmıştır. Sıvılaşma analizleri $\mathrm{Mw}=7.2^{\prime}$ lik bir deprem senaryosu için yapılmış ve çalışma alanındaki 15 metrelik zemin katmanının sıvılaşma potansiyeli belirlenmiştir. Yapılan analizler sonucunda Sahilkent yöresinde $\mathrm{Mw}=7.2^{\prime}$ lik bir deprem senaryosu için herhangi bir sıvılaşma olayının gerçekleşmeyeceği belirlenmiştir. Alüvyon malzemesinin ince daneli malzeme oranının yüksek olması, var olan kum ve siltli kum seviyelerinin ise çok sıkı ince daneli zemin katmanları arasında yer almasının zeminin sıvılaşmaya karşı mukavemetini arttırdığı düşünülmektedir.
\end{abstract}

Anahtar kelimeler: Alüvyon, Bafra kıyı ovası, CPT, Sıvılaşma, Zemin

\begin{abstract}
In this study, liquefaction potential of the alluvial soils consisting of clay, silt, and sand sized materials in Sahilkent (Bafra, Samsun) area was investigated using CPT data. Within the scope of the study, 20 boreholes each having a depth of 15 meters were drilled throughout Bafra district, and one undisturbed soil sample were obtained per meter from 5 of these boreholes located in Sahilkent area. Wet sieve, hydrometer, plastic limit, liquid limit, and natural water content determinations were conducted on 20 samples with high silt and sand content. In the preliminary evaluation, it was determined that there is a liquefaction potential in some regions at different depths, and in order to perform detailed liquefaction analyses, 15-meter-deep CPTu were carried out in 1 meter distance from those 5 borehole locations. In CPTu tests, data including cone tip resistance, sleeve friction, effective stress, relative stiffness, etc. were recorded every $5 \mathrm{~cm}$, and average values of these data for each meter depth were used in the liquefaction analysis. Liquefaction analyses was conducted for an earthquake scenario of $M w=7.2$ and the liquefaction potential of the 15-meter soil layer in the study area was determined. As a result of the analyses, it was determined that no liquefaction will occur for an earthquake scenario of $M w=7.2$ in Sahilkent region. It is thought that high fine-grained content of the alluvium, and the fact that existing clean sand levels are located between fine-grained soil layers increase the resistance of the soil against liquefaction.
\end{abstract}

Keywords: Alluvium, Bafra coastal plain, CPT, Liquefaction, Soil

\footnotetext{
*a Muhammet Oğuz SÜNNETCİ; moguzsunnetci@ktu.edu.tr, Tel: (0462) 377 35 05, orcid.org/0000-0002-5215-3143

${ }^{\mathrm{b}}$ orcid.org/0000-0001-5556-547X
} 


\section{Giriş}

Sıvılaşma, suya doygun granüler zeminlerin sismik yükler altında tekrarlı gerilmelere maruz kalarak zemin iskeletinin yeniden düzenlenmesi, bu sırada boşluk suyu basıncının aşırı derecede yükselerek toplam gerilmeye eşit olması sebebiyle efektif gerilmenin sıfıra düşmesi ve zeminin bir sıvı gibi davranması olarak tanımlanmaktadır. Sıvılaşma sırasında zeminin kayma dayanımı önemli ölçüde azalmakta ve zemin yapısında büyük deformasyonlar meydana gelmektedir. Genellikle sismik yükün kalkmasıyla birlikte sıvılaşma olayının zemin üzerindeki etkisi de sonra ermekte, zemin kayma mukavemetini geri kazanmaktadır (Marcuson, 1978).

Sıvılaşma olayı 1964 yılında Japonya'da meydana gelen Niigata depreminin ardından yerbilimleri dünyasının dikkatini çekmiştir. Niigata depremi sonrasında bilim insanları, zarar gören binaların çok büyük bir kısmının gevşek ve suya doygun zeminler üzerinde inşa edilmiş olduğunu, ayrıca bu binaların çoğunun çok düşük yapısal hasarlarla devrildiğini veya zemine gömüldügüünü fark etmişlerdir. Aynı yıl Kanada'da meydana gelen 9.2 büyüklüğündeki Alaska depreminin ardından benzer olayların gözlenmesiyle birlikte sıvılaşma olay1 mühendisler ve sismologlar tarafindan araştırılmaya başlanmıştır (Davis, 1960; Seed ve Wilson, 1967).

Sıvılaşma olayının belli zeminlerde ve belli koşullar altında geliştiği bilinmektedir (Seed ve Wilson, 1967; Seed ve Idriss, 1971; Iwasaki vd., 1984). Zemin malzemesinin kohezyonu, plastisitesi, rölatif sıkılı̆̆ durumu sıvılaşma potansiyelini doğrudan etkileyen etmenlerdir. Literatürde düşük kohezyonlu siltli zeminlerde, kohezyonsuz kumlu zeminlerde ve az da olsa çakıllı zeminlerde sıvılaşma olayının gerçekleştiği ortaya konmuştur (Youd vd., 1985). Zemin türünden bağımsız olarak boşluk suyu basıncının yükselmesine neden olacak geçirimsiz tabakaların ve sismik bir yükün varlığı sıvılaşma olayının gerçekleşmesinde en önemli faktörlerdir. Seed ve Idriss (1982) tarafından önerilen Çin Kriterine göre bir zeminin sıvılaşabilmesi için aşağıdaki şartları sağlaması gereklidir:

1. Ağırlıkça kil yüzdesi $<\% 15$ olmalı.

2. Likit limit $<\% 35$ olmall.

3. Doğal su muhtevası likit limitin 0.9

katından daha yüksek olmalı.

Bray vd. (2004) bu kriterin her zaman geçerli olmadığını 1999 Kocaeli depreminden etkilenen
Adapazarı'ında yaptıkları çalışmalarla göstermişlerdir. $\mathrm{Bu}$ çalışmada Çin Kriterine uymayan birçok zemin katmanının sıvılaşma gösterdiği belirtilmiştir. Önalp ve Arel (2002) ve Bol vd. (2010), Çin Kriterini 1999 Kocaeli depreminden sonra Adapazarı siltlerine uyarlamışlar ve çeşitli değişiklikler önermişlerdir.

Zeminlerin sıvilaşma potansiyelini irdelemek üzere birçok yöntem ortaya atılmıştır (Seed ve Idriss 1971; Dobry vd., 1981; Seed vd., 1981; Iwasaki vd., 1984). Bu yöntemler temelde zemine etkiyen tekrarlı kayma oranının (CSR) zeminin tekrarlı dayanım oranı (CRR) ile kiyaslanmasina dayanmaktadır. Herhangi bir zemin için CSR $>$ CRR olduğunda bu zemin sıvılaşma potansiyeline sahip olarak değerlendirilmektedir. Zeminlere ait CRR değeri laboratuvar veya arazi deneyleriyle belirlenebilmektedir. Çevirmeli üç eksenli, çevirmeli direkt kesme ve çevirmeli torsiyon deneyleri en çok tercih edilen laboratuvar deneyleriyken, arazide standart penetrasyon testi (SPT), koni penetrasyon testi (CPT) ve jeofizik ölçümler (kayma dalgası hızı, $\mathrm{V}_{\mathrm{s}}$ ) kullanılmaktadır. SPT'nin özellikle örnek alıcı aparata iletilen enerjiye bağlı olarak zaman zaman tutarsız sonuçlar verebilmesi (Robertson ve Wride, 1998), buna karş1lık CPT'nin daha tekrarlanabilir ve sürekli veri alımına izin veren bir yöntem olması sıvılaşma potansiyeli araştırmalarında CPT verilerinin kullanımını son yıllarda önemli ölçüde artmıştır (Dobry vd., 2019; Kurnaz ve Kaya, 2019; Ntritsos ve Cubrinovski, 2020). Birçok araştırmacı (Robertson ve Campanella, 1985; Seed ve de Alba, 1986; Shibata ve Teparaska, 1988; Stark ve Olson, 1995) CPT verileri ile temiz kum ve siltli zeminlerin CRR değerleri arasında bağıntılar önermişlerdir. 1996 yılında Birleşik Devletler Ulusal Deprem Mühendisliği Araştırmaları Merkezi (NCEER) tarafindan Utah'ta düzenlenen sıvılaşma çalıştayında Robertson ve Wride (1998) tarafindan arazi verileri ve edinilen tecrübeler ışığında CPT'nin sıvılaşma potansiyeli araştırmalarında kullanılması amacıyla önerilen metodoloji gerek proje mühendisleri gerekse de bilim insanları tarafindan benimsenmiştir (Youd ve Idriss 2001).

Ülkemizde yapılan sıvılaşma riski/potansiyeli araştırmalarında CPT deney verilerinin kullanıldığı çalışmalar olsa da (Sönmez vd., 2015; Sert vd., 2018), SPT deney verilerinin kullanıldığı çalışmalar çok daha fazladır (Duman, 2013; Esin, 2015; Iş1k vd., 2016; Ateş, 2017). Söz konusu deneylerden elde edilen verilerin kalitesi ve tekrarlanabilirliği göz önüne alındığında bu durumun bir eksiklik olduğu söylenebilir. 
Marmara Bölgesi'nin gerek sismik faaliyetlerin yoğun olması gerekse de Adapazarı silti gibi granüler zeminlerin geniş bir alanda yüzeyleme vermesinden dolayı sıvılaşma riski yüksek olan bir bölge olduğu bilinmektedir. Bununla birlikte Karadeniz Bölgesi'nin sahil kesiminde geniş bir alana yayılan siltli-kumlu alüvyon zeminlerin varlığı ve bu bölgenin Kuzey Anadolu Fayı'na yakın olması nedeniyle sıvılaşma riski bakımından araştırılması gereken bir bölge olduğu da ortadadır. Özellikle Samsun ve Ordu illerinde sıvılaşma riski taşıyan zeminler üzerine yapılan çalışmalar mevcuttur. Ertek (2015) tarafindan yapilan çalışmada Atakum ilçesinin sıvılaşma potansiyeli ve buna bağlı muhtemel oturmalar belirlenmiş, sıvılaşma analizlerinde SPT deney verileri kullanılmıştır. Öztürk (2016) tarafından yapılan çalışmada Tekkeköy bölgesinin sıvilaşma potansiyeli SPT deney verilerini kullanarak Seed ve Idriss (1971) yöntemine göre belirlenmiştir. Dipova ve Cangir (2017) yaptıkları çalışmada CPT deneylerinin istenilen derinliklere ulaşamaması sebebiyle sıvılaşma analizlerinde SPT deney verilerini kullanmak durumunda kalmışlardır.

Bu çalışmada jeolojik, jeomorfolojik ve sismolojik özellikler bakımından sıvılaşma potansiyeline sahip olan Samsun ili Bafra ilçesi Sahilkent yöresindeki alüvyal zeminlerin sıvılaşma potansiyelinin CPT deney verileri kullanılarak belirlenmesi amaçlanmıştır. Çalışma alanının tamamını kaplayan alüvyon malzemesi kil, silt ve kum boyutlu malzemelerden oluşmaktadır. Özellikle silt ve kumlu zeminlerin sıvılaşma potansiyeli taşıdığı bilinmekle birlikte, son zamanlarda yapılan çalışmalar killi zeminlerde dahi sıvılaşma olayının belli koşullar altında gelişebileceğini göstermiştir (Bilge ve Çetin, 2017). Bölgede akarsu tarafından beslenen yeraltı suyu seviyesinin yüzeyden itibaren yaklaşı 2 metre veya daha sığ derinliklerde olması ve birçok yerleşim yerinin bulunması bölgenin sıvılaşma potansiyeli açısından araştırılması gerekliliğini doğurmaktadır. $\mathrm{Bu}$ amaç doğrultusunda aşağıdaki çalışmalar yapılmıştır:
Bafra ilçesinin farklı bölgelerinde 15 metre derinliğinde 20 adet sondaj çalışması yapılmış ve Sahilkent yöresindeki 5 adet sondajdan her metrede bir adet olacak şekilde örselenmemiş zemin örnekleri alınmış,

Zemin örneği alınan sondaj kuyularına yakın olacak şekilde (yatay mesafe $<1 \mathrm{~m}$ ) 5 adet boşluk suyu basıncı ölçümlü Koni Penetrasyon Tesi (CPTu) çalışması yapılarak sıvılaşma analizlerinde kullanılacak olan parametreler elde edilmiş ve aynı zamanda zemin davranış tipi profili belirlenmiş,

- Alınan zemin örneklerinden silt ve kum oranı yüksek olan 20 örnek üzerinde 1slak elek, hidrometre, likit limit, plastik limit ve doğal su muhtevası deneyleri yapılmış,

- $\quad$ Tüm veriler ışığında Youd ve Idriss (2001) tarafından derlenen yönteme göre sıvılaşma analizleri yapılmış,

- $\quad$ Son olarak Iwasaki (1978) tarafindan önerilen yöntemle çalışma alanın sıvılaşma potansiyeli belirlenmiştir.

\section{2. Çalışma alanının jeolojisi}

Çalışma alanı Samsun ili Bafra ilçesinin $12 \mathrm{~km}$ kuzeybatısındaki Sahilkent yöresidir (Şekil 1). Ülkemizin en büyük ikinci drenaj alanına sahip nehri olan Kızılırmak'ın denize döküldüğü Bafra'da nehrin taşıdığı alüvyon malzemesi çok geniş bir alanda yüzeylenme vermektedir. Çalışma alanındaki en genç birim olan bu alüvyon malzemesi Geç Kuvaterner (Holosen) yaşlı yeni alüvyon ve Erken Kuvaterner (Pleistosen) yaşl1 eski alüvyon olarak iki kısımdan oluşmaktadır. Eski alüvyon Kızılırmak'ın sağ ve sol sahillerinde seki ve taraçalar şeklinde gözlenirken yeni alüvyon Karadeniz kıyısına kadar uzanan sulak alanları ve düzlükleri oluşturmaktadır. Her iki birimin yüzeylendiği bölge ise güncel delta düzlüğü veya Bafra kıy ovas1 olarak isimlendirilmektedir (Turoğlu, 2010). Bu birimlerin altında Eosen yaşlı volkanik kayaçlar yer almaktadır (Temizel vd., 2016; Firat Ersoy ve Karaca, 2019). 


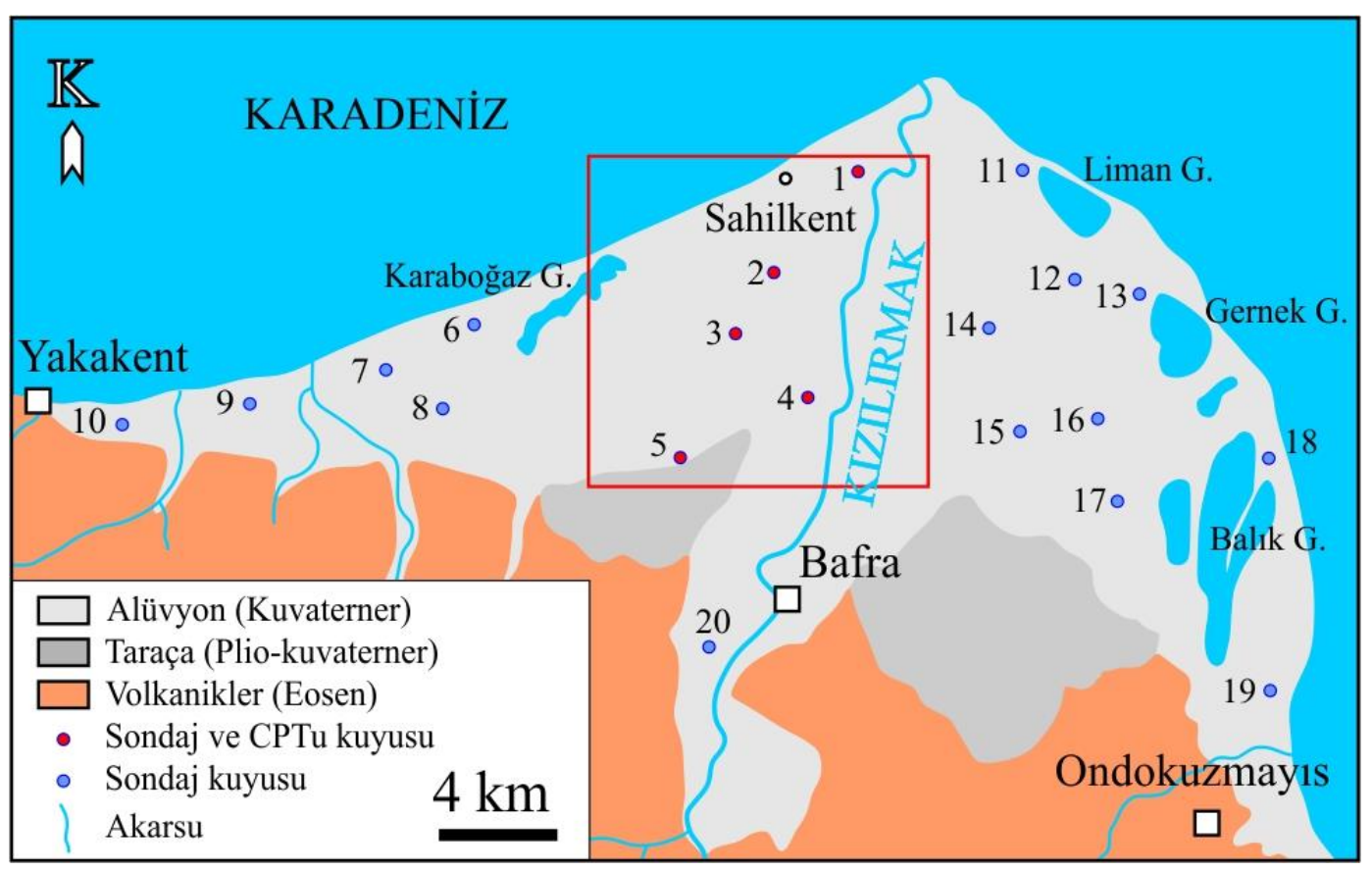

Şekil 1. Çalışma alanının jeoloji haritası ile sondaj ve CPT lokasyonları

\section{Malzeme ve yöntem}

\subsection{Sondaj çalışmaları}

Çalışma kapsamında 15 metre derinliğinde 20 adet sondaj yapılmış ve çalı̧̧ma alanı olan Sahilkent yöresindeki 5 adet sondajdan her bir metrede 1 adet örselenmemiş zemin örneği temin edilmiştir. Örnekler özel olarak yaptırılan $60 \mathrm{~cm}$ uzunluğunda (maksimum örnek uzunluğu $50 \mathrm{~cm}$ ) ince yanaklı UD tip örnek alıcılarla alınmış ve alınan örnekler hemen alt ve üst yüzeyleri parafinlenerek streç filme sarılmıştır (Şekil 2). Örselenmemiş örnek alımından sonra sondaj tabanında kalan diğer 50 cm'lik kısım örselenme etkisini ortadan kaldırmak amacıyla auger ile geçildikten sonra sıradaki örselenmemiş örnek temin edilmiş, böylece her 1 metrede 1 adet $50 \mathrm{~cm}$ uzunluğunda örselenmemiş örnek alınmıştır. Elde edilen örnekler üzerinde ASTM standartlarına (ASTM, 2009, 2010, 2011) uygun olarak sslak elek analizi, hidrometre, likit limit, plastik limit ve doğal su muhtevası tayinleri yapılmıştır.

\section{2. $C P T$ çalışmaları}

Çalı̧̧ma kapsamında Sahilkent yöresinde 5 adet CPT yapılmış (Şekil 2), CPT lokasyonları bu bölgedeki 5 adet sondaja yakın olacak şekilde (yatay mesafe $\leq 1 \mathrm{~m}$ ) seçilmiştir. Zemine ait CSR değerinin hesaplanmasında efektif gerilme değerleri kullanılacağı için CPT deneyleri piezokoni (CPTu) adı verilen, koni uç direnci ve kenar sürtünmesine ek olarak gözenek suyu basıncını da ölçebilen koni kullanılarak yapılmış ve tüm kuyularda 15 metre derinliğe inilmiştir. Deney sırasında koni uç direnci, kenar sürtünmesi, gözenek suyu basıncı ve rölatif sıkılık dahil olmak üzere alüvyon malzemesine ait birçok parametre her 5 cm'de bir kaydedilmiştir. Sıvılaşma analizlerinde bu veriler her 1 metre derinlik için ortalamaları alınarak kullanılmıştır. 


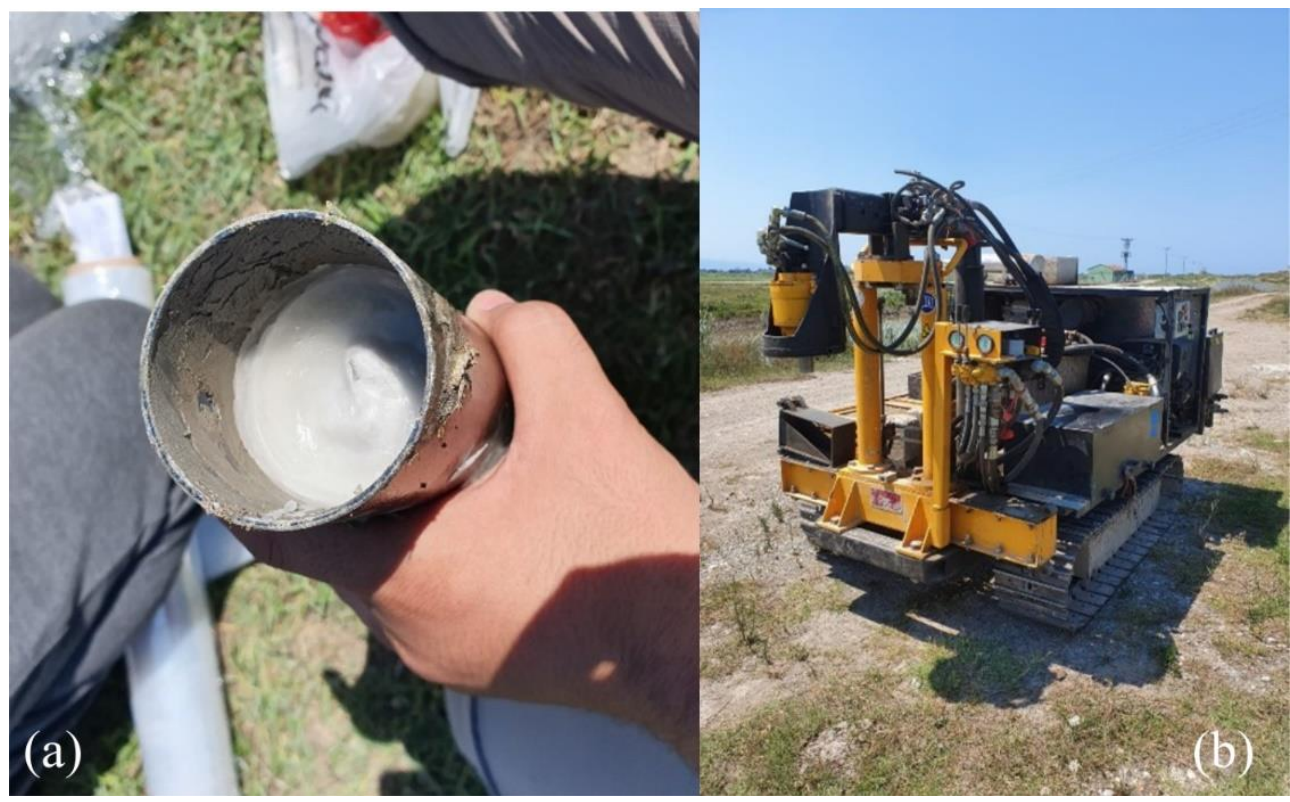

Şekil 2. (a) Alınan örselenmemiş zemin örneklerin parafinle kaplanması. (b) CPTu deneylerinde kullanılan Gouda ${ }^{\circledR}$ mobil CPT cihazı

CPT verileri kullanılarak yapılan sıvılaşma analizlerinde Youd ve Idriss (2001) tarafindan derlenen metodoloji kullanılmıştır. Bu metodoloji temel olarak Robertson ve Wride (1998) tarafindan önerilen yöntemi esas alsa da başka araştırmacıların önerilerini de kapsamaktadır. Yöntemin detaylı açıklaması CPT Verileri ile Sıvılaşma Analizi bölümünde verilmiştir.

\subsection{CPT verileri ile sıvılaşma analizi}

CPT 1930'lu yıllarda ilk kez uygulanmış olsa da (Huizinga, 1942; Plantema, 1948) günümüzdeki halini 1960'ların ikinci yarısından itibaren alan ve giderek daha yaygin olarak kullanılmakta olan bir arazi deneyidir. Begemann (1969) koni ucundaki direncin belirlenmesine ek olarak konik ucun kenarına eklediği adhezyon kaplamasıyla kenar sürtünmelerini de hesaplamayı başarmış ve bu şekilde uç direnci/kenar sürtünmesi oranını kullanarak zemin katmanlarının sınıflandırılabilmesini sağlamıştır. Senneset ve Janbu (1985) koni ucuna boşluk suyu basıncını ölçen bir aparat yerleştirerek kumlu ve killi zeminlerin efektif kayma direnci parametrelerini belirlemiştir. 1980'li y1llardan itibaren ise CPT verileri zeminlerin sıvılaşma tehlikesinin belirlenmesinde kullanılmaya başlanmıştır (Robertson ve Campanella, 1985; Shibata ve Teparaska, 1988). Neredeyse 70 yıllık arazi deneyimi, vaka çalışması ve gözlem birikimi ile CPT deneyi günümüzde zeminlere ait $\mathrm{CRR}$ değerinin arazide belirlenmesinde kullanılan en yaygın ve güvenilir deney haline gelmiştir (Dobry vd., 2019; Kurnaz ve Kaya, 2019; Ntritsos ve Cubrinovski, 2020).

CPT verileri yardımıyla 7.5 büyüklüğündeki bir deprem için zemine ait CRR değeri aşağıdaki eşitliklerle belirlenebilmektedir (Robertson ve Wride, 1998):

$\left(q_{c l N}\right)_{c s}<50$ ise $\mathrm{CRR}_{7.5}=0.833\left[\left(q_{c l N}\right)_{c s} / 1000\right]+$ 0.05

$\left(q_{c l N}\right)_{c s} \leq 160$ ise $\mathrm{CRR}_{7.5}=93\left[\left(q_{c l N}\right)_{c s} / 1000\right]^{3}+$ 0.08

burada;

$\left(\mathrm{q}_{\mathrm{c} 1 \mathrm{~N}}\right)_{\mathrm{CS}}$ : Temiz kum için normalize koni uç direnci,

$\mathrm{CRR}_{7.5}$ : $\mathrm{Mw}=7.5$ depremler için zemine ait tekrarlı dayanım oranıdır.

Seed and Idriss (1971) bir deprem durumunda zemine etkiyecek olan CSR değerini belirlemek için aşağıdaki eşitliği önermişlerdir:

$$
C S R=0.65\left(\frac{a_{\max }}{g}\right)\left(\frac{\sigma_{v 0}}{\sigma_{v 0}^{\prime}}\right) r_{d}
$$

burada; $\mathrm{a}_{\max }$ deprem tarafindan yüzeyde üretilen en büyük yatay yer ivmesi, g yerçekimi ivmesi, $\sigma_{\mathrm{v} 0}$ ve $\sigma_{\text {v0 }}^{\prime}$ sirasıyla incelenen derinlikteki toplam ve efektif gerilmeler, $r_{d}$ ise zemin esnekliğinden ileri gelen gerilme azaltma katsayısıdır. Liao ve Whitman (1986)'a göre $r_{d}$ aşağıdaki eşitliklerle belirlenebilmektedir: 
$\mathrm{z} \leq 9.15 \mathrm{~m}$ ise $\mathrm{r}_{\mathrm{d}}=1.0-0.00765 \mathrm{z}$

$9.15 \mathrm{~m}<\mathrm{z} \leq 23 \mathrm{~m}$ ise $\mathrm{r}_{\mathrm{d}}=1.174-0.0267 \mathrm{z}$

Ancak bilgisayar ortamında daha kolay programlanabilmesi nedeniyle aşağıdaki eşitlik rutin mühendislik uygulamalarında kullanılabilmektedir (Youd ve Idriss, 2001):

$r_{d}=\left(1-0.4113 z^{0.5}+0.04052 z+0.001753 z^{1.5}\right) /\left(1-0.4177 z^{0.5}+0.05729 z-0.006205 z^{1.5}+0.00121 z^{2}\right)$
Daha önce de bahsedildiği gibi, incelenen zemin profilinin herhangi bir derinliğinde CSR $>$ CRR olması zeminin sıvılaşma riski taşıdığı anlamına gelmektedir. Yapılan arazi gözlemleri CRR değerlerinin artan normal ve efektif gerilmelerle arttığını göstermiştir. Bu nedenle zeminlere ait CRR değerleri belirlenirken arazide ölçülen koni uç direnci $\left(\mathrm{q}_{\mathrm{c}}\right)$ değeri efektif gerilmeye göre normalize edilmelidir (Robertson ve Wride, 1998):

$$
\begin{aligned}
& q_{c 1 N}=C_{Q}\left(\frac{q_{c}}{P_{a}}\right) \\
& C_{Q}=\left(\frac{P_{a}}{\sigma^{\prime}{ }_{v 0}}\right)^{n}
\end{aligned}
$$

burada; $q_{c I N}$ normalize koni uç direnci, $C_{Q}$ koni uç direnci düzeltme faktörü, $P_{a} \sigma_{v 0}^{\prime}$ ile aynı birimde olmak üzere 1 atmosfere karşılık gelen basınç ( 0.1 MPa veya $100 \mathrm{KPa}$ ), $n$ zemin türüne bağlı üstel değişkendir. $C_{Q}$ için 1.7 'den büyük değerler kullanılmamalıdır. $n$ temiz kum zeminler için 0.5 , kil zeminler için 1.0, silt ve siltli kum zeminler için ise 0.5-1.0 arasında değerler almaktadır. Normalize koni uç direnci $\left(q_{c I N}\right)$ birimsiz bir değerdir.

CPT deneyi sırasında ölçülen koni uç direnci $\left(q_{c}\right)$ ve kenar sürtünmesi $\left(f_{s}\right)$ değerleri zeminin dane boyu dağılımına ve plastisitesine bağlı olarak değişmektedir. İri daneli zeminler tipik olarak yüksek koni uç direnci - düşük kenar sürtünmesi değerlerine sahip olurken ince daneli ve plastik zeminler düşük koni uç direnci - yüksek kenar sürtünmesi değerlerine sahiptir. Bu farklılık CPT burada $\mathrm{z}$ metre cinsinden analiz yapılan zemin katmanının derinliğidir. oran 1 ad 1 verilen $f_{s} / q_{c}$ oranından faydalanarak zeminlerin sinıflandırılabilmesini mümkün kılmaktadır (Şekil 3). Zemin sınıfını, daha doğru bir tanımla zemin davranışı tipini karakterize eden $I_{c}$ değeri aşağıdaki eşitlikle hesaplanmaktadır:

$$
I_{c}=\left[(3.47-\log Q)^{2}+(1.22+\log F)^{2}\right]^{0.5}
$$

burada;

$$
\begin{aligned}
& Q=\left(\frac{q_{c}-\sigma_{v 0}}{P_{a}}\right)\left(\frac{P_{a}}{\sigma_{v 0}^{\prime}}\right)^{n} \\
& F(\%)=\frac{f_{s}}{q_{c}-\sigma_{v 0}} \times 100
\end{aligned}
$$

Robertson ve Wride (1998) Eşitlik 5'te öncelikle $n$ $=1.0$ alınarak $\mathrm{Q}$ ve buna bağlı $I_{c}$ değerinin hesaplanmasını önermiştir. Hesaplanan $I_{c}$ değeri 2.6'dan büyükse zeminin killi zemin sınıfinda olduğu ve sıvılaşma göstermeyeceği kabul edilerek analiz sonlandırılır. Eğer hesaplanan $I_{c}$ değeri 2.6'dan küçükse $n=0.5$ alınarak $\mathrm{Q}$ ve $\mathrm{I}_{\mathrm{c}}$ değerleri tekrar hesaplanır. Bu durumda hesaplanan $\mathrm{I}_{\mathrm{c}}$ değeri 2.6'dan küçükse zeminin plastik olmayan granüler zemin sınıfinda olduğu kabul edilir ve $I_{c}$ değeri sıvılaşma dayanımının belirlenmesinde kullanılır. Eğer $\mathrm{n}=0.5$ için hesaplanan $\mathrm{I}_{\mathrm{c}}$ değeri 2.6'dan büyükse $\mathrm{n}=0.7$ alınarak $\mathrm{Q}$ ve $\mathrm{I}_{\mathrm{c}}$ değerleri yeniden hesaplanır ve $I_{c}$ değeri bu haliyle sıvılaşma dayanımının belirlenmesinde kullanılır. 


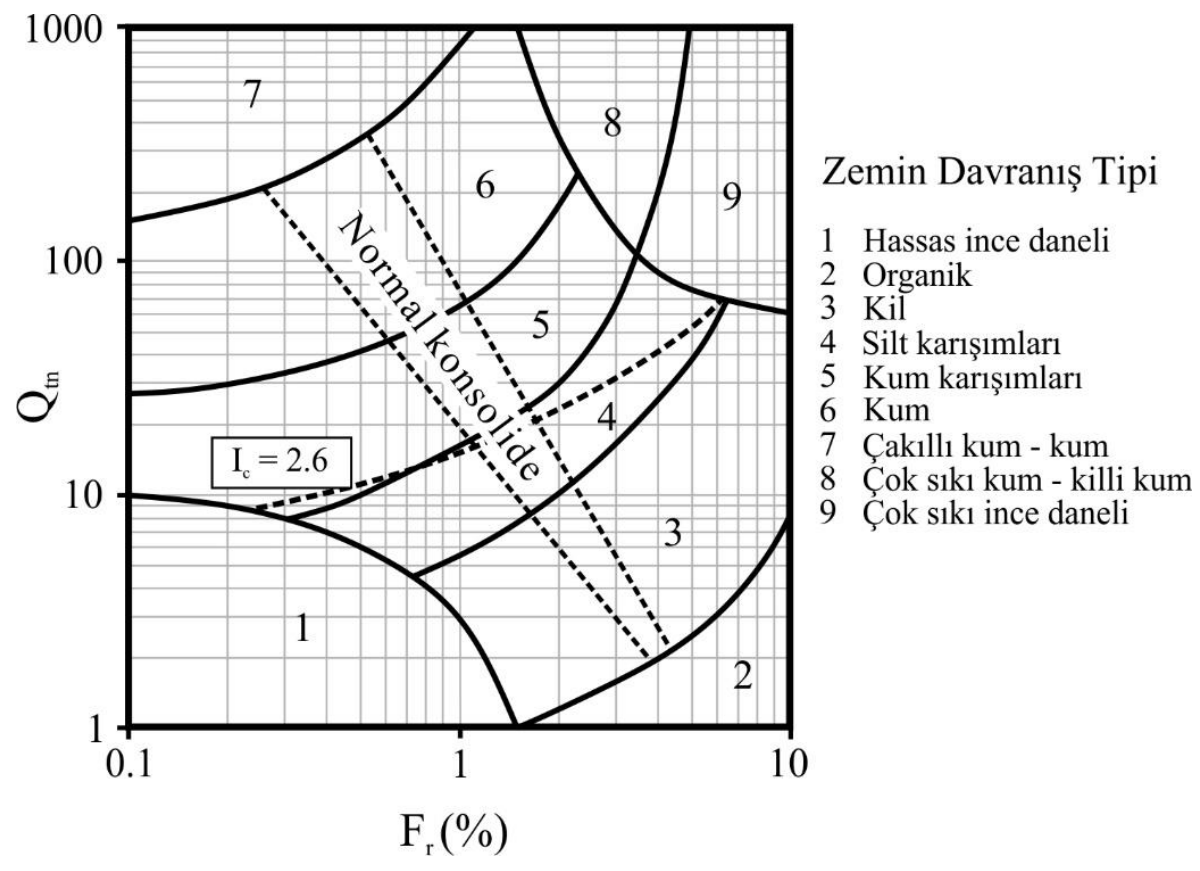

Şekil 3. Robertson (1990) tarafından önerilen Zemin Davranış Tipi sınıflaması

Siltli zeminler için belirlenen normalize koni uç direnci $\left(q_{c l N}\right)$ temiz kumlar (Birleştirilmiş Zemin Sinıflaması'nda SW-SP sinıfindaki zeminler; ASTM, (2011) için aşağıdaki eşitlik kullanılarak düzeltilir (Robertson ve Wride, 1998):

$\left(q_{c l N}\right)_{c s}=\mathrm{K}_{\mathrm{c}} q_{c l N}$

burada;

$\mathrm{I}_{\mathrm{c}} \leq 1.64$ için $\mathrm{K}_{\mathrm{c}}=1.0$

$\mathrm{I}_{\mathrm{c}}>1.64$ için $\mathrm{K}_{\mathrm{c}}=-0.403 \mathrm{I}_{\mathrm{c}}{ }^{4}+5.581 \mathrm{I}_{\mathrm{c}}{ }^{3}-21.63 \mathrm{I}_{\mathrm{c}}{ }^{2}$

$$
+33.75 \mathrm{I}_{\mathrm{c}}-17.88
$$

Yukarıda verilen eşitlikler ile belirlenen CRR değeri yalnızca 7.5 büyüklüğündeki depremler için uygulanabilmektedir. Temiz kumlar için belirlenen $\left(q_{c I N}\right)_{c s}$ değerleri büyüklük düzeltme faktörü (MSF) denilen katsayılarla çarpılarak CRR değerleri deprem büyüklüğüne bağlı olarak arttırılır ya da azaltılır. Genel olarak MSF aşağıdaki şekilde uygulanır:

$\mathrm{FS}=\left(\mathrm{CRR}_{7.5} / \mathrm{CSR}\right) \mathrm{MSF}$ burada FS güvenlik sayısıdır.

Literatürde farklı araştırmacıların önerdiği MSF değerleri bulunmasına karşın (Seed ve Idriss, 1982; Ambraseys, 1988; Arango, 1996; Andrus ve Stokoe, 1997) bunlardan en çok tercih edileni Seed ve Idriss (1982) tarafından önerilen düzeltme faktörüdür:

$\mathrm{MSF}=10^{2.24} /\left(\mathrm{M}_{\mathrm{w}}\right)^{2.56}$

burada $\mathrm{M}_{\mathrm{w}}$ deprem moment büyüklüğüdür.

\section{Bulgular}

\subsection{CPTu verileri}

CPTu deneylerinden elde edilen ham (arazi) koni uç direnci $\left(\mathrm{q}_{\mathrm{c}}\right)$ ve kenar sürtünmesi $\left(\mathrm{f}_{\mathrm{s}}\right)$ değerlerinin derinlikle değişimi Şekil 4 ve Şekil 5 'te verilmiştir. Şekil 4 ve 5 incelendiğine özellikle 10-13 metreler arasında yüksek $q_{c}$ - düşük $f_{s}$ değerlerinin elde edildiği görülmektedir. $\mathrm{Bu}$ veriler sıvılaşma potansiyeline sahip granüler zeminlerin varlığına işaret etmektedir. 


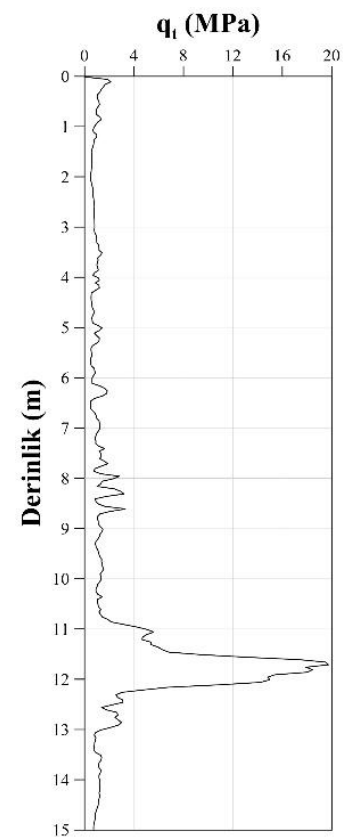

CPTu-1

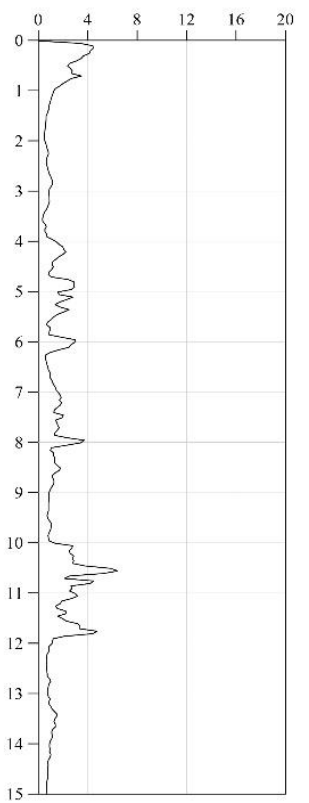

CPTu-2

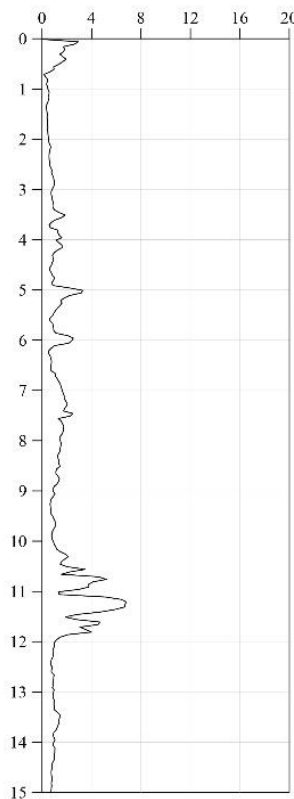

CPTu-3

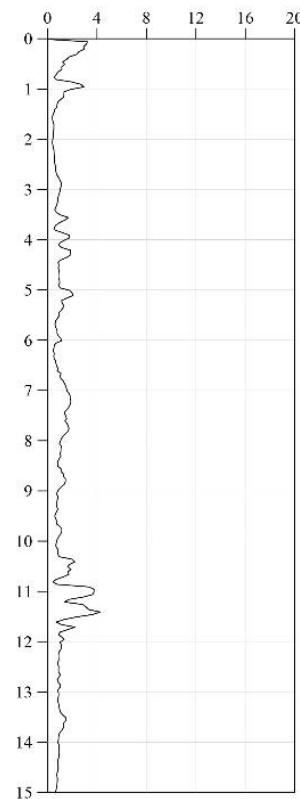

CPTu-4

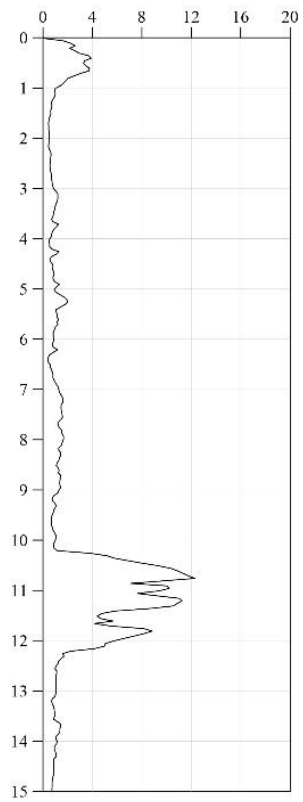

CPTu-5

Şekil 4. CPTu kuyularındaki $\mathrm{q}_{\mathrm{c}}$ değerlerinin derinlikle değişimi

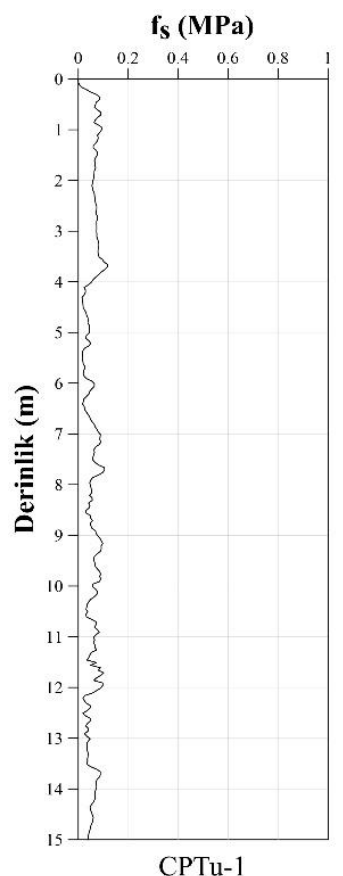

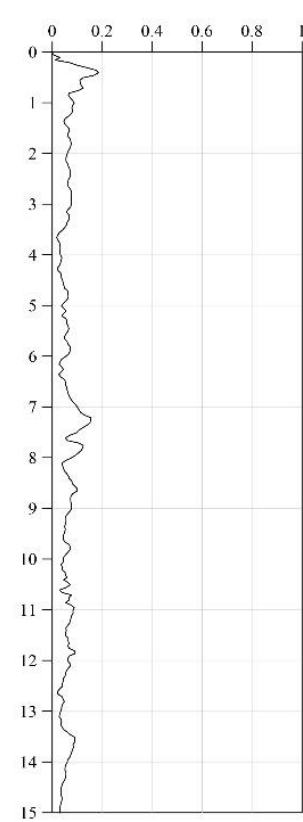

CPTu-2

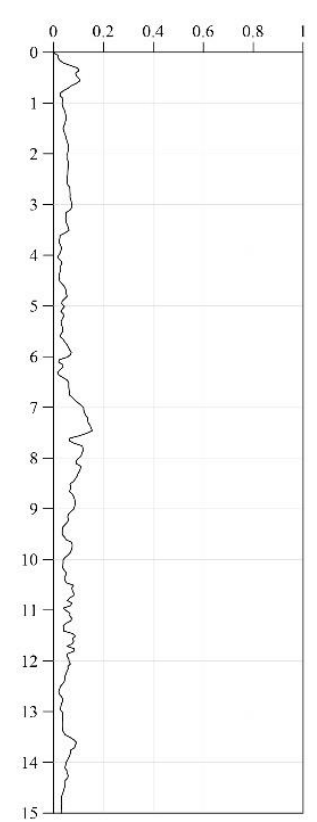

CPTu-3

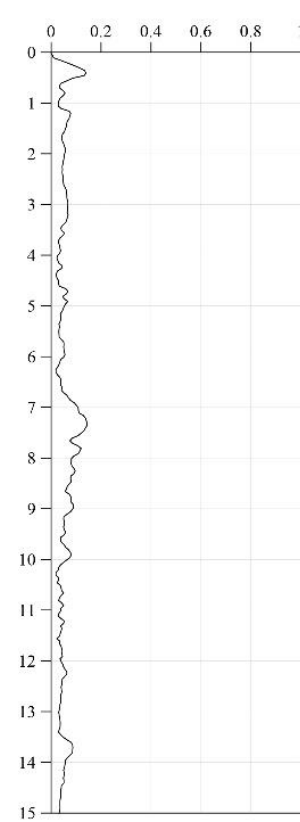

CPTu-4

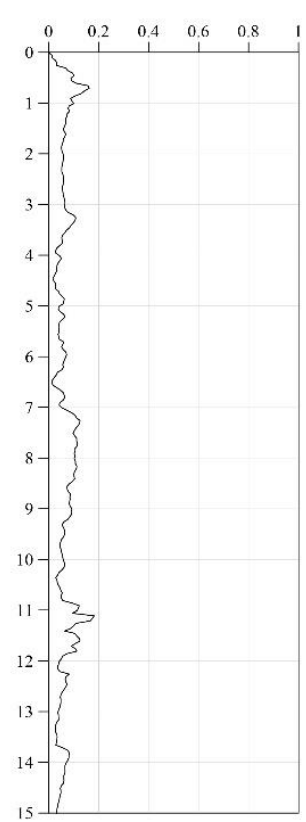

CPTu-5

Şekil 5. CPTu kuyularındaki $f_{s}$ değerlerinin derinlikle değişimi

Daha önce de belirtildiği gibi, elde edilen CPT verilerinin her 1 metre derinlik için ortalaması alınmıştır. Daha sonra arazide belirlenen $q_{c}$ ve $f_{s}$ değerleri üzerinde Youd ve Idriss (2001) tarafından önerilen yönteme göre düzeltmeler yapılarak sıvılaşma analizlerinde kullanılacak olan $\mathrm{q}_{\mathrm{c} \ln (\mathrm{cs})}, \mathrm{I}_{\mathrm{c}}$,
$\mathrm{K}_{\mathrm{c}}, \mathrm{r}_{\mathrm{d}}, \mathrm{CSR}$ ve CRR parametreleri belirlenmiştir. Sıvılaşma analizlerinde kullanılmış olan parametrelerden bazıları Tablo 1'de özetlenmiştir. 
Tablo 1. Sıvılaşma analizlerinde kullanılan $I_{c}$ ve $\mathrm{q}_{\mathrm{c} 1 \mathrm{~N}, \mathrm{CS}}$ parametreleri

\begin{tabular}{lllllllllll}
\hline $\mathbf{z}$ & \multicolumn{2}{l}{$\mathbf{C P T u}-\mathbf{1}$} & \multicolumn{2}{l}{ CPTu-2 } & \multicolumn{2}{l}{$\mathbf{C P T u}-3$} & \multicolumn{2}{l}{ CPTu-4 } & \multicolumn{2}{l}{ CPTu-5 } \\
$(\mathbf{m})$ & $\mathbf{I}_{\mathbf{C}}$ & $\mathbf{q}_{\mathbf{c 1 N}, \mathbf{C S}}$ & $\mathbf{I}_{\mathbf{C}}$ & $\mathbf{q}_{\mathbf{c 1 N}, \mathbf{C S}}$ & $\mathbf{I}_{\mathbf{C}}$ & $\mathbf{q}_{\mathbf{c l N}, \mathbf{C S}}$ & $\mathbf{I}_{\mathbf{C}}$ & $\mathbf{q}_{\mathbf{c 1 N}, \mathbf{C S}}$ & $\mathbf{I}_{\mathbf{C}}$ & $\mathbf{q}_{\mathbf{c 1 N}, \mathbf{C S}}$ \\
\hline 1 & 2.497 & 55.594 & 2.221 & 83.810 & 2.527 & 57.930 & 2.315 & 60.401 & 2.300 & 85.778 \\
2 & 2.647 & 40.526 & 2.636 & 46.060 & 2.761 & 34.142 & 2.976 & 81.592 & 2.749 & 49.026 \\
3 & 2.677 & 45.581 & 2.656 & 51.322 & 2.639 & 43.317 & 2.728 & 47.354 & 2.816 & 50.257 \\
4 & 2.618 & 59.124 & 2.739 & 48.866 & 2.826 & 87.983 & 2.928 & 99.675 & 2.653 & 58.941 \\
5 & 2.951 & 80.530 & 2.656 & 101.631 & 2.886 & 88.781 & 2.909 & 97.188 & 2.684 & 49.053 \\
6 & 2.684 & 51.567 & 2.890 & 106.565 & 2.835 & 92.547 & 2.661 & 48.495 & 2.613 & 51.000 \\
7 & 2.773 & 75.153 & 2.706 & 50.525 & 2.807 & 52.609 & 2.933 & 51.183 & 2.968 & 50.193 \\
8 & 2.801 & 101.581 & 2.745 & 67.603 & 2.770 & 70.546 & 2.838 & 70.714 & 2.842 & 66.940 \\
9 & 2.925 & 79.141 & 2.787 & 51.817 & 2.909 & 58.565 & 3.000 & 57.521 & 2.891 & 60.008 \\
10 & 2.934 & 126.403 & 3.127 & 49.104 & 3.135 & 48.674 & 3.160 & 49.620 & 3.111 & 50.108 \\
11 & 2.744 & 108.325 & 2.666 & 78.145 & 2.820 & 77.096 & 2.654 & 33.855 & 2.271 & 84.289 \\
12 & 2.547 & 192.207 & 2.919 & 81.708 & 2.650 & 81.065 & 2.816 & 62.914 & 2.416 & 106.108 \\
13 & 2.504 & 65.221 & 3.317 & 43.280 & 3.200 & 40.221 & 3.171 & 41.042 & 2.646 & 37.564 \\
14 & 3.174 & 122.374 & 3.169 & 45.140 & 3.168 & 43.649 & 3.179 & 43.013 & 3.150 & 40.235 \\
15 & 3.250 & 123.281 & 3.399 & 40.935 & 3.345 & 40.301 & 3.362 & 40.669 & 3.348 & 42.935 \\
$z:$ derinlik & & & & & & & & & \\
\hline
\end{tabular}

\subsection{Zemin davranış tipi profili ve yeraltı suyu}

Alüvyon malzemesinin zemin davranışı sinıflamas1 Robertson (2016) tarafından önerilen yöntemle normalize koni uç direnci $\left(\mathrm{Q}_{\mathrm{tn}}\right)$ ve sürtünme oranı $\left(\mathrm{F}_{\mathrm{r}}\right)$ verileri kullanılarak yapılmıştır. Her bir CPT lokasyonuna ait zemin davranış tipinin derinlikle değişimi Şekil 6'da verilmiştir. Buna göre çalışma alanında kil - siltli kil (3), killi silt (4), siltli kum (5), kum (6), çok sık1 kum - killi kum (8) ve çok sık1 ince daneli (9) zemin sinıflarında birimler yer almaktadır. Sondaj çalışmaları 1şı̆̆ında bölgedeki yeraltı suyu seviyesi 2 metre olarak belirlenmiştir.

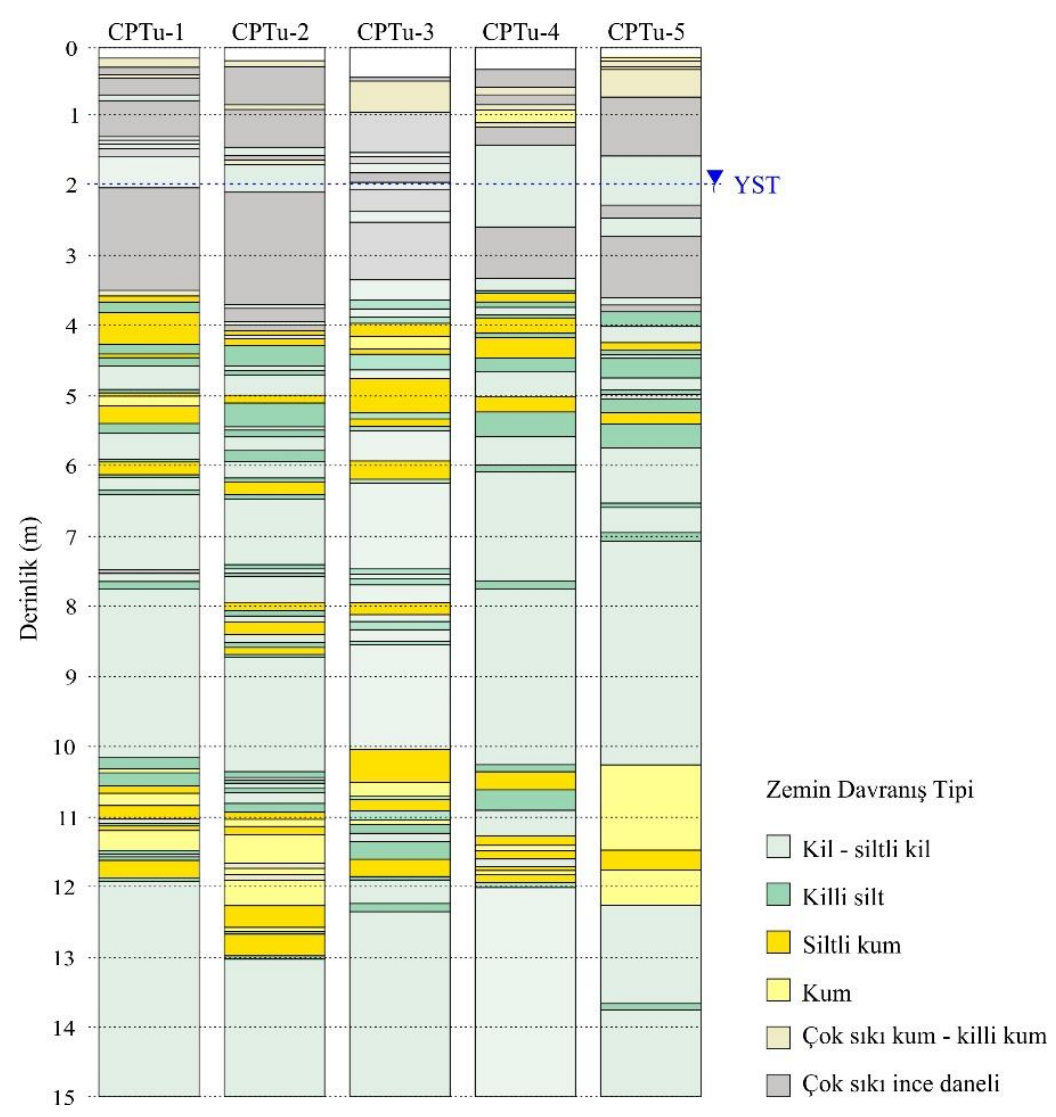

Şekil 6. Çalışma alanındaki alüvyon malzemesinin zemin davranış tipi profili 
4.3. Çalı̧̧ma alanındaki zemin katmanlarının sıvilaşma potansiyeli

Daha önce de belirtildiği üzere çalışma kapsamında Bafra yöresinde 20 adet sondaj yapılmış ve bu sondajların 5 tanesinden örselenmemiş zemin örnekleri temin edilmiştir. Toplamda 75 adet sondaj örneği temin edilmiş olmasına rağmen çalışma alanındaki zeminlerin sıvılaşma potansiyeli hakkında ön bir değerlendirme yapmak amacıyla CPTu verileri yardımıyla hazırlanan zemin profillerinde kum-kum karışımları olarak belirlenen derinliklerden alınan 20 adet örnek seçilmiştir. Seçilen bu örnekler üzerinde ASTM standartlarına uygun olarak sslak elek, hidrometre, likit limit, plastik limit deneyleri yapılmış ve örneklerin doğal su muhtevaları tayin edilmiştir (ASTM, 2009, 2010, 2011). Daha sonra bu veriler Seed vd. (2003) tarafından önerilen plastisite sıvılaşma potansiyeli grafiğine aktarılarak alüvyon malzemesinin sıvılaşma potansiyeli araştırılmıştır. Yapılan deneylere ait sonuçlar Tablo 2 ve 3'te verilmiştir.

Tablo 2. Örneklerin dane boyu dağılımları

\begin{tabular}{|c|c|c|c|c|c|c|c|c|c|}
\hline $\begin{array}{c}\text { Örnek } \\
\text { No }\end{array}$ & $\begin{array}{l}\text { Kil } \\
(\%)\end{array}$ & $\begin{array}{l}\text { Silt } \\
(\%)\end{array}$ & $\begin{array}{c}\text { Kum } \\
(\%)\end{array}$ & $\begin{array}{l}\text { FC } \\
(\%)\end{array}$ & $\begin{array}{c}\text { Örnek } \\
\text { No }\end{array}$ & $\begin{array}{c}\text { Kil } \\
(\%)\end{array}$ & $\begin{array}{l}\text { Silt } \\
(\%)\end{array}$ & $\begin{array}{c}\text { Kum } \\
(\%)\end{array}$ & $\begin{array}{l}\text { FC } \\
(\%)\end{array}$ \\
\hline 1 & 30 & 58 & 12 & 88 & 11 & 50 & 38 & 12 & 88 \\
\hline 2 & 32 & 43 & 25 & 75 & 12 & 22 & 67 & 11 & 89 \\
\hline 3 & 31 & 59 & 10 & 90 & 13 & 18 & 59 & 23 & 77 \\
\hline 4 & 18 & 54 & 28 & 72 & 14 & 34 & 56 & 10 & 90 \\
\hline 5 & 28 & 63 & 9 & 91 & 15 & 38 & 50 & 12 & 88 \\
\hline 6 & 30 & 58 & 12 & 88 & 16 & 32 & 59 & 9 & 91 \\
\hline 7 & 42 & 47 & 11 & 89 & 17 & 33 & 53 & 14 & 86 \\
\hline 8 & 50 & 43 & 7 & 93 & 18 & 21 & 56 & 23 & 77 \\
\hline 9 & 63 & 29 & 8 & 92 & 19 & 26 & 60 & 14 & 86 \\
\hline 10 & 52 & 39 & 9 & 93 & 20 & 29 & 61 & 10 & 90 \\
\hline
\end{tabular}

FC: 200 no'lu elekten geçen ince daneli malzeme orant.

Tablo 2 verileri incelendiğinde örneklerin ince daneli malzeme oranının \%70'ten fazla olduğu görülmektedir. Örneklerin kil içerikleri \%18-63 arasında, silt içerikleri \%29-67 arasında, kum içerikleri ise \% 7-28 arasında değişmektedir. Hiçbir örnekte çakıl boyutunda malzeme bulunmamaktadır. Örneklere ait dane boyu dağılımı grafikleri, literatürde sıvılaşma potansiyeli gösteren zeminlerin dane boyu dağılımları ile kıyaslanmıştır (Şekil 7). Şekil 7'den de görülebileceği üzere örneklerin bir kısmına ait dane boyu dağılımları Potansiyel Sıvılaşma Aralığı bölgesine düşmektedir.

Tablo 3. Örneklerin Atterberg limitleri ve doğal su muhtevaları

\begin{tabular}{|c|c|c|c|c|c|c|c|c|c|}
\hline $\begin{array}{c}\text { Örnek } \\
\text { No }\end{array}$ & $\begin{array}{l}\text { PL } \\
(\%)\end{array}$ & $\begin{array}{l}\mathbf{L L} \\
(\%)\end{array}$ & $\begin{array}{c}\text { PI } \\
(\%)\end{array}$ & $\begin{array}{l}\mathbf{W}_{\mathbf{n}} \\
(\%)\end{array}$ & $\begin{array}{c}\text { Örnek } \\
\text { No }\end{array}$ & $\begin{array}{l}\text { PL } \\
(\%)\end{array}$ & $\begin{array}{l}\text { LL } \\
(\%)\end{array}$ & $\begin{array}{c}\text { PI } \\
(\%)\end{array}$ & $\begin{array}{l}W_{\mathbf{n}} \\
(\%)\end{array}$ \\
\hline 1 & 21 & 41 & 20 & 30 & 11 & 34 & 57 & 23 & 39 \\
\hline 2 & 20 & 32 & 12 & 33 & 12 & 22 & 34 & 12 & 27 \\
\hline 3 & 19 & 46 & 27 & 30 & 13 & 25 & 38 & 13 & 30 \\
\hline 4 & 27 & 41 & 14 & 22 & 14 & 22 & 34 & 12 & 25 \\
\hline 5 & 23 & 40 & 17 & 33 & 15 & 29 & 62 & 33 & 38 \\
\hline 6 & 24 & 35 & 11 & 28 & 16 & 26 & 54 & 28 & 34 \\
\hline 7 & 22 & 46 & 24 & 29 & 17 & 32 & 53 & 21 & 38 \\
\hline 8 & 29 & 58 & 29 & 33 & 18 & 26 & 45 & 19 & 34 \\
\hline 9 & 32 & 74 & 42 & 28 & 19 & 23 & 35 & 12 & 29 \\
\hline 10 & 31 & 75 & 44 & 33 & 20 & 21 & 43 & 22 & 30 \\
\hline
\end{tabular}

Tablo 3 incelendiğinde örneklerin likit limitlerinin \%32-75 arasında, plastik limitlerinin \%19-34 arasında, plastisite indislerinin \%11-44 arasında, doğal su muhtevalarının ise \%22-39 arasında değiştiği görülmektedir. 


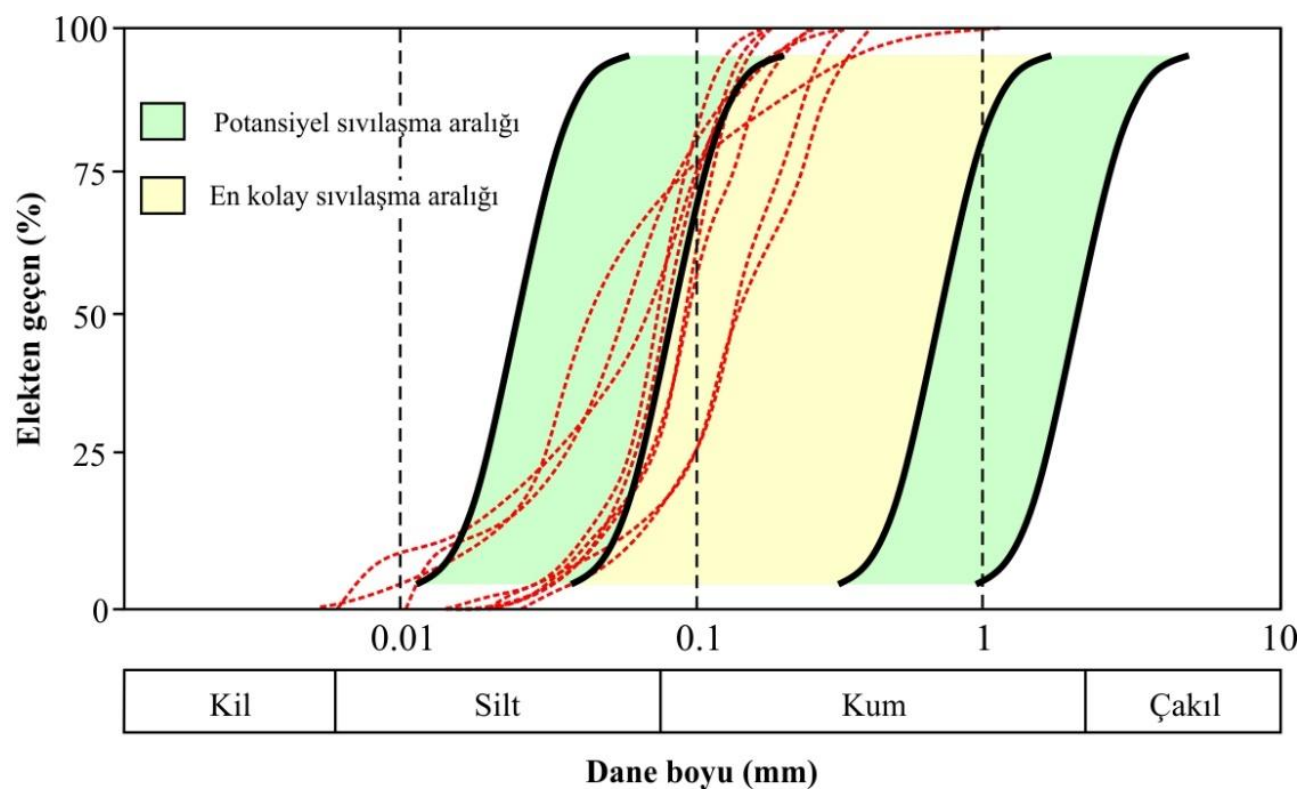

Şekil 7. Zemin örneklerinin dane boyu dağılımlarının literatürde sıvılaşma potansiyeli gösteren zeminlerin dane boyu dağılımları ile kıyaslanması (Balkema, 1997)

Seed vd. (2003) tarafından önerilen sıv1laşma potansiyeli grafiği sadece aşağıdaki koşullarda kullanılabilmektedir:

a. $\mathrm{PI}>\% 12$ ve $\mathrm{FC} \geq \% 20$

b. $\mathrm{PI}<\% 12$ ve $\mathrm{FC} \geq \% 35$ burada FC, 200 no'lu elekten geçen ince daneli malzeme oranıdır. Tablo 2 ve 3 incelendiğinde 2 ve 6 numaralı örneklerin (b) şartını, diğer tüm örneklerin ise (a) şartını sağladığı görülmektedir. Örneklerin Seed vd. (2003) tarafindan önerilen grafikteki dağılımları Şekil 8'de verilmiştir.

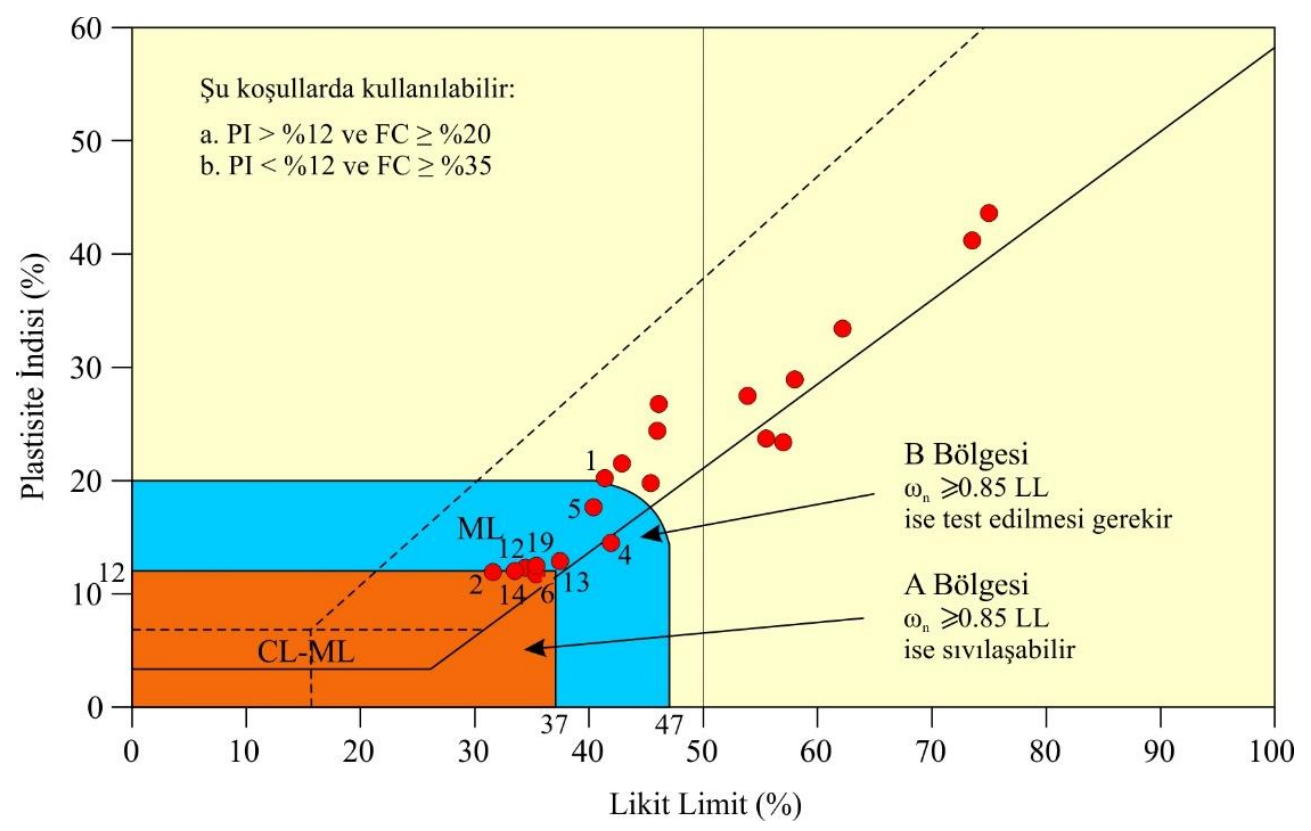

Şekil 8. Örneklerin Seed vd. (2003) tarafindan önerilen plastisite - sıvılaşma potansiyeli grafiğindeki dağılımı

Plastisite - sıvılaşma potansiyeli grafiği incelendiğinde $1,2,4,5,6,12,13,14$ ve 19 numaralı örneklerin A ve/veya B bölgelerinde yer aldığı görülmektedir.
Şekil 7'de A veya B bölgelerinde yer alan zemin örneklerinin sıvılaşma potansiyeli hakkında ön değerlendirme yapabilmek için doğal su muhtevalarının likit limitlerinin 0.85 katına eşit veya fazla olması gerekmektedir $\left(\mathrm{W}_{\mathrm{n}} \geq 0.85^{*} \mathrm{LL}\right)$. 
Tablo 4 incelendiğinde 2 numaralı örneğin bu şartı sağladığı; $6,12,13$ ve 19 numaralı örneklerin ise sınır değere çok yakın olduğu görülmektedir.
Dolayısıyla çalışma alanındaki zemin katmanlarının sıvılaşma potansiyelinin detaylı bir şekilde analiz edilmesi gerektiği görülmektedir.

Tablo 4. Örneklerin sıvılaşma değerlendirmesinde kullanılan sınır koşul parametreleri

\begin{tabular}{lccccccccc}
\hline $\begin{array}{c}\text { Örnek } \\
\text { No }\end{array}$ & $\begin{array}{c}\text { PI } \\
(\boldsymbol{\%})\end{array}$ & $\begin{array}{c}\text { FC } \\
(\boldsymbol{\%})\end{array}$ & $\mathbf{L L} * \mathbf{0 . 8 5}$ & $\begin{array}{c}\mathbf{W}_{\mathbf{n}} \\
(\boldsymbol{\%})\end{array}$ & $\begin{array}{c}\text { Örnek } \\
\mathbf{N o}\end{array}$ & $\begin{array}{c}\text { PI } \\
(\boldsymbol{\%})\end{array}$ & $\begin{array}{c}\mathbf{F C} \\
(\boldsymbol{\%})\end{array}$ & $\mathbf{L L} * \mathbf{0 . 8 5}$ & $\begin{array}{c}\mathbf{W}_{\mathbf{n}} \\
(\boldsymbol{\%})\end{array}$ \\
\hline 1 & 20 & 88 & 34.9 & 30 & 11 & 34 & 88 & 48.5 & 39 \\
2 & 12 & 75 & 27.2 & 33 & 12 & 22 & 89 & 28.9 & 27 \\
3 & 27 & 90 & 39.1 & 30 & 13 & 25 & 77 & 32.3 & 30 \\
4 & 14 & 72 & 34.9 & 22 & 14 & 22 & 90 & 28.9 & 25 \\
5 & 17 & 91 & 34.0 & 33 & 15 & 29 & 88 & 52.7 & 38 \\
6 & 11 & 88 & 29.8 & 28 & 16 & 26 & 91 & 45.9 & 34 \\
7 & 24 & 89 & 39.1 & 29 & 17 & 32 & 86 & 45.1 & 38 \\
8 & 29 & 93 & 49.3 & 33 & 18 & 26 & 77 & 38.3 & 34 \\
9 & 42 & 92 & 62.9 & 28 & 19 & 23 & 86 & 29.8 & 29 \\
10 & 44 & 93 & 63.8 & 33 & 20 & 21 & 90 & 36.6 & 30 \\
\hline
\end{tabular}

\subsection{Sivılaşma analizleri}

Sıvılaşma potansiyeli incelemelerinin ilk aşamasında çalışma alanında yüzeylenen alüvyon malzemesinin sıvılaşmaya karşı güvenlik sayıları Robertson ve Wride (1998) tarafindan önerilen eșitlikle (Eș. 10) belirlenmiștir. Yapılan sıvılașma analizlerinde çalışma alanındaki en büyük yatay yer ivmesi (PGA) değeri Türkiye Deprem Tehlike Haritası (AFAD, 2019) verilerine uygun şekilde $0.18 \mathrm{~g}$ olarak alınmıştır (Şekil 9). Bu değer 0.2g'den düşük olduğu için aktif fay uzaklık düzeltmesi yapılmaksızın olduğu gibi kullanılmıştır (Towhata,
2008). Deprem büyüklüğü olarak Samsun'da gerçekleşen en büyük kayıtll deprem olan 26 Kasım 1943 Ladik depremi (Ms=7.2) baz alınmıştır. Youd ve Idriss (2001) $6<\mathrm{Ms}<8$ arasındaki deprem büyüklüklerinin doğrudan $\mathrm{Mw}$ skalasına dönüştürülerek kullanılabileceğini belirtmiştir. $\mathrm{Ms}=\mathrm{Mw}=7.2$ büyüklük için deprem büyüklüğü düzeltme faktörü (MSF) Eş. 11 kullanılarak:

$\mathrm{MSF}=10^{2.24} /(7.2)^{2.56}=1.11$

olarak hesaplanmıştır.

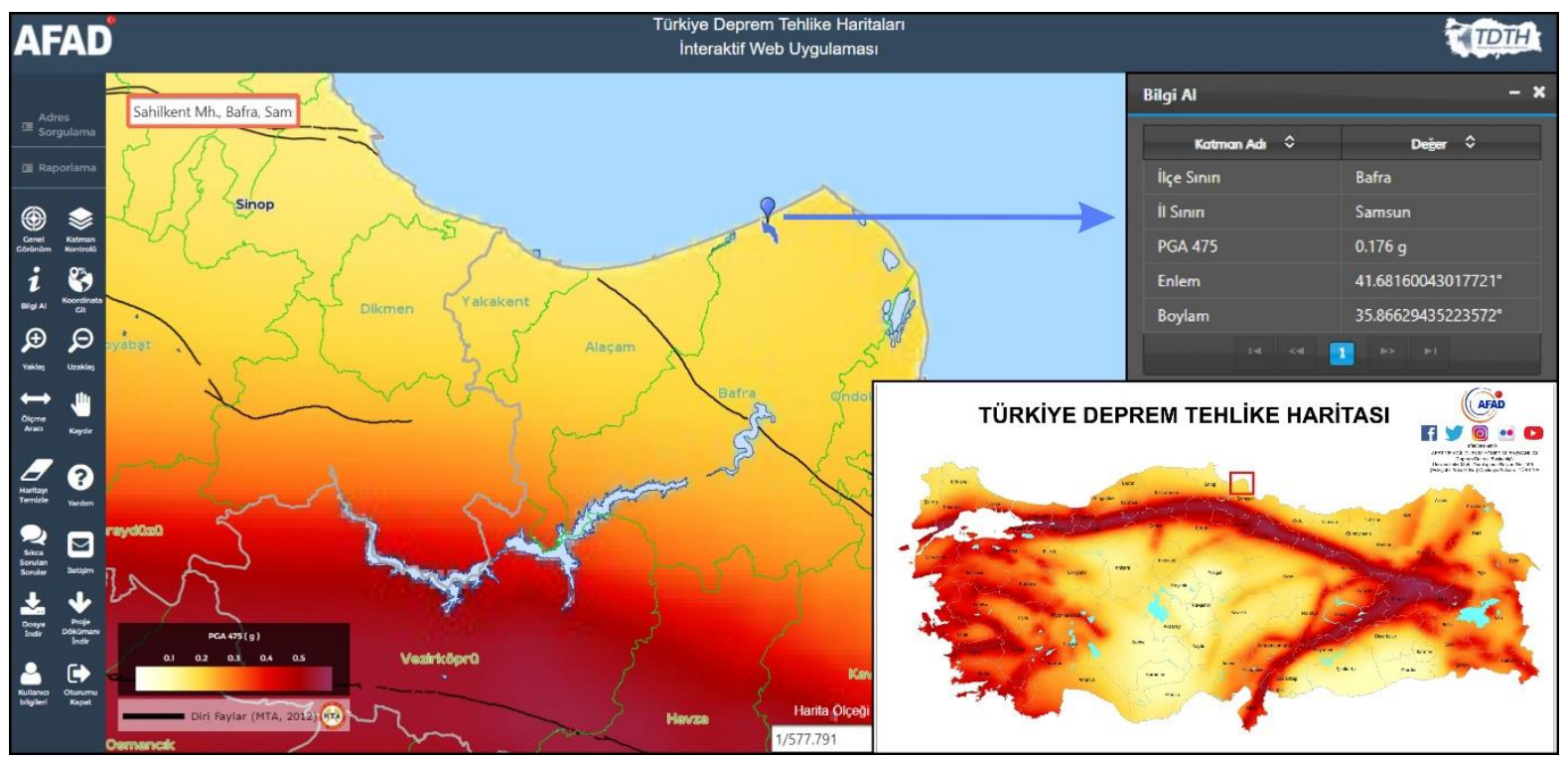

Şekil 9. Sahilkent yöresinin Türkiye Deprem Tehlike Haritası'ndaki yeri ve hesaplanan PGA değeri (AFAD, 2019)

Zemin profiline ait güvenlik sayıları belirlendikten sonra Iwasaki (1978) tarafından önerilen yöntem kullanılarak 15 metrelik zemin profilinin sıvılaşma potansiyeli belirlenmiştir: 


$$
\mathrm{LPI}=\int_{0}^{15 m} F \times w(z) d z
$$

Burada;

$$
w(z)=10-0.5 z
$$

$\mathrm{F}=0(\mathrm{FS}>1$ ise $)$

$\mathrm{F}=1-\mathrm{FS} \quad(\mathrm{FS}<1$ ise $)$

LPI: sıvılaşma potansiyeli indeksi (bkz. Tablo 5), $\mathrm{z}$ : metre cinsinden derinlik,

w: derinlik ağırlık düzeltme faktörüdür.

Elde edilen LPI değerleri kullanılarak Tablo 5'e göre potansiyel sıvılaşmanın şiddeti belirlenmiştir.

Tablo 5. Hesaplanan LPI değerlerine göre sıvılaşma şiddetinin belirlenmesi (Iwasaki, 1978)

\begin{tabular}{ll}
\hline Sıvllaşmanın Şiddeti & LPI \\
\hline Az - Yok & LPI $=0$ \\
Küçük & $0<$ LPI $<5$ \\
Orta & $5<$ LPI $<15$ \\
Büyük & $15<$ LPI \\
\hline
\end{tabular}

Yapılan sıvılaşma analizlerinde belirlenen CSR, CRR, $\mathrm{FS}_{7.2}$ ve LPI değerleri Tablo 6'da verilmiştir. Çalışma alanındaki zemin katmanlarının tamamının sıvılaşma şiddetinin $\mathrm{Az}-$ Yok sınıfında olduğu sonucuna varılmıştır.

\section{Tartışma ve sonuçlar}

$\mathrm{Bu}$ çalışmada Samsun ili Bafra ilçesi Sahilkent yöresinde yüzeylenen suya doygun kumlu-siltli alüvyon malzemesinin sıvılaşma potansiyeli araştırılmıştır. Bölgedeki zemin katmanlarının sıvılaşma potansiyeli hakkında ön bir değerlendirme yapabilmek amacıyla çalışma alanında 5 adet karotlu sondaj yapılmış ve örselenmemiş zemin örnekleri temin edilmiştir. $\mathrm{Bu}$ örnekler üzerinde indeks ve plastik özellik tayinleri yapılarak zemin katmanlarının sıvılaşma potansiyeli Seed vd. (2003) tarafından önerilen yöntemle belirlenmiş ve örneklerin bir kısmının 'Sıvılaşabilir', bir kısmının ise 'Test Edilmesi Gerekir' bölgelerinde yer aldığ 1 görülmüştür. $\mathrm{Bu}$ bulgular göz önünde bulundurularak çalışma alanında 15 metre derinliğinde 5 adet CPTu deneyi yapılmış ve elde edilen verilerle Youd ve Idriss (2001) tarafından önerilen yönteme göre sıvılaşma analizleri yapılmıştır. Sıvılaşma analizleri Samsun ilinde gözlenen en büyük deprem olan 1943 Ladik depremi $(\mathrm{Mw}=7.2)$ baz alınarak yapıılmış ve PGA değeri $0.18 \mathrm{~g}$ olarak alınmıştır.

Yapılan analizler sonucunda Sahilkent yöresinde 7.2 büyüklüğündeki bir deprem için herhangi bir sıvılaşma olayının gözlenmeyeceği sonucuna varılmıştır. Sondaj çalışmalarıyla alınan örnekler üzerinde yapılan indeks özellik tayinlerinden elde edilen veriler değerlendirildiğinde, alüvyon malzemesinin yüksek ince daneli malzeme $(<0.005$ $\mathrm{mm}$ ) oranına sahip olmasinın bu durumun en önemli nedeni olduğu görülmektedir. İnce daneli malzemelerin zemin malzemesinin kohezyonunu arttırdığı ve böylece zemine sıvılaşma olayına karşı fazladan dayanım kazandırdığı bilinmektedir (Youd ve Idriss, 2001). Bu durum Tablo 1'de açık olarak gözlenebilmektedir: tablodaki $I_{c}$ değerlerinin büyük bir çoğunluğu 2.6'dan fazladır ki bu durum söz konusu zemin tabakasının kil sınıfında olduğu anlamına gelmektedir. Bölgede sıvılaşmaya karşı duyarlı temiz kum seviyeleri olmasına karşın bu seviyelerin kalın kil - siltli kil sınıfındaki tabakalar arasında yer alması sıvılaşma olayının beklenmemesinin bir başka nedenidir (Ishihara, 1985). 
Tablo 6. CPTu lokasyonlarında her bir metre için hesaplanan sıvılaşma potansiyeli değerleri

\begin{tabular}{|c|c|c|c|c|c|c|c|c|c|c|c|c|c|c|c|c|c|c|c|c|}
\hline \multirow{2}{*}{$\mathbf{z}(\mathbf{m})$} & \multicolumn{5}{|c|}{ CPTu-1 } & \multicolumn{5}{|c|}{ CPTu-2 } & \multicolumn{4}{|c|}{ CPTu-3 } & \multicolumn{3}{|c|}{ CPTu-4 } & \multicolumn{3}{|c|}{ CPTu-5 } \\
\hline & CSR & CRR & $\mathbf{F S}_{7.2}$ & LPI & SŞ & CSR & CRR & $\mathbf{F S}_{7.2}$ & LPI & SŞ & CSR & CRR FS $_{7.2}$ & LPI & SŞ & CSR CRR FS F.2 I & LPI & SŞ & CSR CRR FS & LPI & SŞ \\
\hline 1 & 0.041 & 0.096 & 2.60 & 0 & Az-Yok & 0.031 & 0.135 & 4.83 & 0 & Az-Yok & 0.031 & 0.0983 .51 & 0 & Az-Yok & 0.0320 .1003 .47 & 0 & Az-Yok & 0.0250 .1396 .17 & 0 & Az-Yok \\
\hline 2 & 0.046 & 0.084 & 2.03 & 0 & Az-Yok & 0.035 & 0.088 & 2.79 & 0 & Az-Yok & 0.044 & 0.0781 .96 & 0 & Az-Yok & 0.0330 .1314 .41 & 0 & Az-Yok & 0.0320 .0913 .15 & 0 & Az-Yok \\
\hline 3 & 0.054 & 0.088 & 1.81 & 0 & Az-Yok & 0.042 & 0.093 & 2.45 & 0 & Az-Yok & 0.051 & 0.0861 .88 & 0 & Az-Yok & 0.0400 .0892 .48 & 0 & Az-Yok & 0.0400 .0922 .55 & 0 & Az-Yok \\
\hline 4 & 0.053 & 0.099 & 2.08 & 0 & Az-Yok & 0.044 & 0.091 & 2.30 & 0 & Az-Yok & 0.048 & 0.1433 .31 & 0 & Az-Yok & 0.0400 .1724 .77 & 0 & Az-Yok & 0.0430 .0992 .55 & 0 & Az-Yok \\
\hline 5 & 0.050 & 0.129 & 2.86 & 0 & Az-Yok & 0.038 & 0.178 & 5.19 & 0 & Az-Yok & 0.038 & 0.1454 .24 & 0 & Az-Yok & 0.0350 .1655 .23 & 0 & Az-Yok & 0.0400 .0912 .53 & 0 & Az-Yok \\
\hline 6 & 0.040 & 0.093 & 2.59 & 0 & Az-Yok & 0.034 & 0.193 & 6.30 & 0 & Az-Yok & 0.035 & 0.1544 .88 & 0 & Az-Yok & 0.0330 .0903 .03 & 0 & Az-Yok & 0.0360 .0922 .84 & 0 & Az-Yok \\
\hline 7 & 0.037 & 0.113 & 3.39 & 0 & Az-Yok & 0.033 & 0.092 & 3.10 & 0 & Az-Yok & 0.034 & 0.0943 .06 & 0 & Az-Yok & 0.0330 .0923 .10 & 0 & Az-Yok & 0.0350 .0922 .92 & 0 & Az-Yok \\
\hline 8 & 0.037 & 0.177 & 5.31 & 0 & Az-Yok & 0.034 & 0.109 & 3.56 & 0 & Az-Yok & 0.034 & 0.1133 .69 & 0 & Az-Yok & 0.0340 .1133 .69 & 0 & Az-Yok & 0.0350 .1083 .43 & 0 & Az-Yok \\
\hline 9 & 0.036 & 0.126 & 3.89 & 0 & Az-Yok & 0.033 & 0.093 & 3.13 & 0 & Az-Yok & 0.035 & 0.0993 .14 & 0 & Az-Yok & 0.0340 .0983 .20 & 0 & Az-Yok & 0.0360 .1003 .09 & 0 & Az-Yok \\
\hline 10 & 0.035 & 0.268 & 8.50 & 0 & Az-Yok & 0.033 & 0.091 & 3.06 & 0 & Az-Yok & 0.035 & 0.0912 .89 & 0 & Az-Yok & 0.0350 .0912 .89 & 0 & Az-Yok & 0.0360 .0922 .84 & 0 & Az-Yok \\
\hline 11 & 0.034 & 0.140 & 4.57 & 0 & Az-Yok & 0.032 & 0.124 & 4.31 & 0 & Az-Yok & 0.033 & 0.1234 .14 & 0 & Az-Yok & 0.0340 .0782 .54 & 0 & Az-Yok & 0.0340 .1364 .44 & 0 & Az-Yok \\
\hline 12 & 0.031 & 0.740 & 26.5 & 0 & Az-Yok & 0.029 & 0.131 & 5.02 & 0 & Az-Yok & 0.030 & 0.1304 .81 & 0 & Az-Yok & $0.0310 .103 \quad 3.69$ & 0 & Az-Yok & 0.0310 .1916 .84 & 0 & Az-Yok \\
\hline 13 & 0.028 & 0.106 & 4.21 & 0 & Az-Yok & 0.028 & 0.086 & 3.41 & 0 & Az-Yok & 0.029 & 0.0843 .22 & 0 & Az-Yok & 0.0290 .0843 .22 & 0 & Az-Yok & 0.0290 .0813 .10 & 0 & Az-Yok \\
\hline 14 & 0.027 & 0.152 & 6.25 & 0 & Az-Yok & 0.027 & 0.088 & 3.62 & 0 & Az-Yok & 0.028 & 0.0863 .41 & 0 & Az-Yok & 0.0280 .0863 .41 & 0 & Az-Yok & 0.0280 .0843 .33 & 0 & Az-Yok \\
\hline 15 & 0.026 & 0.153 & 6.53 & 0 & Az-Yok & 0.026 & 0.084 & 3.59 & 0 & Az-Yok & 0.027 & 0.0843 .45 & 0 & Az-Yok & 0.0270 .0843 .45 & 0 & Az-Yok & 0.0270 .0863 .54 & 0 & Az-Yok \\
\hline
\end{tabular}




\section{Katkı Belirtme}

$\mathrm{Bu}$ çalışma Karadeniz Teknik Üniversitesi Bilimsel Araştırma Projeleri Koordinasyon Birimi tarafindan FBA-2019-8434 ve FDK-2019-8228 kodlu projeler ile desteklenmiştir.

\section{Kaynaklar}

AFAD. (2018). Türkiye Deprem Tehlike Haritası. Ankara: Afet ve Acil Durum Yönetimi Başkanlı̆̆ı. $\quad$ Erişim adresi: https://www.turkiye.gov.tr/afad-turkiye-depremtehlike-haritalari

Ambraseys, N. N. (1988). Engineering seismology. Earthquake Engineering and Structural Dynamics, $17, \quad 1-105$. https://doi.org/10.1002/eqe.4290170102.

Andrus, R. D. and Stokoe, K. H. II. (1997). Liquefaction resistance based on shear wave velocity. Proceedings of the NCEER Workshop on Evaluation of Liquefaction Resistance of Soils (ss. 89-128). New York.

Arango, I. (1996). Magnitude scaling factors for soil liquefaction evaluations. Journal of Geotechnical Engineering, 122(11), 929-936. https://doi.org/10.1061/(ASCE)07339410(1996)122:11(929)

Ateş, A. (2017). Gölyaka (Düzce) imara esas yerleşim alanındaki zeminlerin SPT ve sismik hız verileriyle sıvılaşma riskinin araştırılması. Politeknik Dergisi, 20(4), 753-763. https://doi.org/10.2339/politeknik.368977

ASTM. (2009). Standard Test Methods For ParticleSize Distribution (Gradation) Of Soils Using Sieve Analysis. ASTM D6913-04(2009)e1, West Conshohocken, PA.

ASTM. (2010). Standard Test Methods For Liquid Limit, Plastic Limit, and Plasticity Index Of Soils. ASTM D4318-10e1, West Conshohocken, PA.

ASTM. (2011). Standard Practice For Classification Of Soils For Engineering Purposes (Unified Soil Classification System). ASTM D2487-11, West Conshohocken, PA.

Begemann, H. K. (1965). The friction jacket cone as an aid in determining the soil profile. Proc. 6th Int. Conf. Soil Mech. Found. Eng., Vol. I (ss. 17-20). Toronto.

Bilge, H. T. ve Çetin, K. Ö. (2017). Silt-Kil Karışımı Zeminlerin Sıvılaşma Potansiyellerinin Belirlenmesi. 4. Uluslararasl Deprem Mühendisliği ve Sismoloji Konferansı (ss. 1119). Eskişehir.
Bol, E., Önalp, A., Arel, E., Sert, S. and Özocak, A. (2010). Liquefaction of silts: the Adapazari criteria. Bulletin of Earthquake Engineering, 8(4), 859-873. https://doi.org/10.1007/s10518010-9174-x

Bray, J. D., Sancio, R. B., Durgunoglu, T., Onalp, A., Youd, T. L., Stewart, J. P., Seed, R. B., Cetin, O. K., Bol, E., Baturay, M. B., Christensen, C., and Karadayilar, T. (2004). Subsurface characterization at ground failure sites in Adapazari, Turkey. Journal of Geotechnical and Geoenvironmental Engineering, 130(7), 673685. https://doi.org/10.1061/(ASCE)10900241(2004)130:7(673)

Davis, T. N. (1960). A field report on the Alaska earthquakes of April 7, 1958. Bulletin of the Seismological Society of America, 50(4), 489510.

Dipova, N. ve Cangir, B. (2017). Lara-Kundu (Antalya) düzlüğünün sıvilaşma şiddeti indeksine (LSI) dayalı sıvılaşma haritası. Geological Engineering Journal/Jeoloji Mühendisligi Dergisi, $\quad 41(1), \quad 31-46$. https://doi.org/10.24232/jmd.311839

Dobry, R., Stokoe, K. H., Ladd, R. S. and Youd, T. L. (1981). Liquefaction susceptibility from S-wave velocity. ASCE National Convention (ss. 1-8). New York.

Dobry, R., Thevanayagam, S., El-Sekelly, W., Abdoun, T. and Huang, Q. (2019). Large-scale modeling of preshaking effect on liquefaction resistance, shear wave velocity, and CPT tip resistance of clean sand. Journal of Geotechnical and Geoenvironmental Engineering, 145(10), 04019065.

https://doi.org/10.1061/(ASCE)GT.19435606.0002080

Duman, E. S. (2013). Erzincan il merkezi ve çevresindeki zeminlerin standart penetrasyon deneyi verileri kullanılarak sıvılaşma potansiyelinin belirlenmesi. Yüksek Lisans Tezi, Karadeniz Teknik Üniversitesi Fen Bilimleri Enstitüsü, Trabzon.

Ersoy, A. F. and Karaca, Z. (2019). Determination of groundwater parameters for drinking and agricultural use in the coastal region of engiz aquifer system, Samsun (Turkey). Arabian Journal of Geosciences, 12(6), 198. https://doi.org/10.1007/s12517-019-4365-5

Ertek, M. K. (2015). Slvilaşma potansiyelinin belirlenmesi ve oturmalara etkisinin incelenmesi: Atakum örneği. Yüksek Lisans Tezi, Ondokuz Mayıs Üniversitesi Fen Bilimleri Enstitüsü, Samsun. 
Esin, G. (2015). Coğrafi bilgi sistemi kullanılarak Burhaniye (Balıkesir) yerleşim alanının sıvılaşma duyarlılık haritasının oluşturulması. Yüksek Lisans Tezi, Balıkesir Üniversitesi Fen Bilimleri Enstitüsü, Balıkesir.

Huizinga, T. K. (1942). Grondmechanica (Soil Mechanics). Amsterdam: VTK Leuven.

Ishihara, K. (1985). Stability of natural deposits during earthquakes. Proceedings of the Eleventh International Conference on Soil Mechanics and Foundation Engineering (ss. 321-376). San Francisco.

Işık, A., Ünsal, N., Gürbüz, A. ve Şişman, E. (2016). Fethiye yerleşim alanındaki zeminlerin spt ve kayma dalga hızı verileriyle sıvılaşma potansiyelinin değerlendirilmesi. Gazi Üniversitesi Mühendislik ve Mimarlık Fakültesi Dergisi, 31(4), 1027-1037. https://doi.org/10.17341/gazimmfd.278458

Iwasaki, T. (1978). A practical method for assessing soil liquefaction potential based on case studies at various sites in Japon. Proc. Second Int. Conf. Microzonation Safer Construction Research Application (ss. 885-896). San Francisco.

Iwasaki, T., Arakawa, T. and Tokida, K. I. (1984). Simplified procedures for assessing soil liquefaction during earthquakes. International Journal of Soil Dynamics and Earthquake Engineering, 3(1), 49-58. https://doi.org/10.1016/0261-7277(84)90027-5

Kurnaz, T. F. and Kaya, Y. (2019). A novel ensemble model based on GMDH-type neural network for the prediction of CPT-based soil liquefaction. Environmental Earth Sciences, 78(11), 339. https://doi.org/10.1007/s12665-019-8344-7

Liao, S. S. and Whitman, R. V. (1986). A catalog of liquefaction and non-liquefaction occurrences during earthquakes. Massachusetts: Department of Civil Engineering, Massachusetts Institute of Technology.

Marcuson, W. F. III. (1978). Definition of terms related to liquefaction. Journal of Geotechnical Engineering Division, 104(9), 1197-1200.

Ntritsos, N. and Cubrinovski, M. (2020). A CPT-based effective stress analysis procedure for liquefaction assessment. Soil Dynamics and Earthquake Engineering, 131, 106063. https://doi.org/10.1016/j.soildyn.2020.106063

Önalp, A. ve Arel, E. (2002). Siltlerin sıvılaşma yeteneği: Adapazarı kriteri. Zemin Mekaniği ve Temel Mühendisliği Dokuzuncu Ulusal Kongresi (ss. 363-372). Ankara.
Öztürk, S. (2016). Sivılaşmaya karşı jet grout yöntemi ile zemin iyileştirilmesi: Samsun-Tekkeköy örneği. Yüksek Lisans Tezi, Karadeniz Teknik Üniversitesi Fen Bilimleri Enstitüsü, Trabzon.

Plantema, G. (1948). Construction and method of operating a new deep sounding apparatus. Proceedings of the Second International Conference on Soil Mechanics and Foundation Engineering (ss. 277). Rotterdam.

Balkema, A. A. (1997). Handbook on Liquefaction Remediation on Reclaimed Land. Rotterdam: Taylor and Francis.

Robertson, P. K. (1990). Soil classification using the cone penetration test. Canadian Geotechnical Journal, 27(1), 151-158. https://doi.org/10.1139/t90-014

Robertson, P. K. (2016). Cone penetration test (cpt)based soil behaviour type (sbt) classification system-an update. Canadian Geotechnical Journal, 53(12), 1910-1927. https://doi.org/10.1139/cgj-2016-0044

Robertson, P. K. and Campanella, R. G. (1985). Liquefaction potential of sands using the CPT. Journal of Geotechnical Engineering, 111(3), 384-403. https://doi.org/10.1061/(ASCE)07339410(1985)111:3(384)

Robertson, P. K. and Wride, C. E. (1998). Evaluating cyclic liquefaction potential using the cone penetration test. Canadian Geotechnical Journal, 35(3), 442-459. https://doi.org/10.1139/t98-017

Seed, H. B. and De Alba, P. (1986). Use of SPT and CPT tests for evaluating the liquefaction resistance of sands. Proceedings of Use of in Situ Tests in Geotechnical Engineering (In Situ '86) (ss. 281302). Blacksburg, ABD.

Seed, R. B., Cetin, K. Ö., Moss, R. E. S., Kammerer, A. M., Wu, J., Pestana, J. M., Riemer, M. F., Sancio, R. B., Bray, J. D., Kayen, R. E. and Faris, A. (2003). Recent advances in soil liquefaction engineering: a unified and consistent framework. 26th Annual ASCE Los Angeles Geotechnical Spring Seminar (ss. 1-72) California.

Seed, H. B. and Idriss, I. M. (1971). Simplified procedure for evaluating soil liquefaction potential. Journal of Soil Mechanics \& Foundations Div. 97, 1249-1273.

Seed, H. B. and Wilson, S. D. (1967). The turnagain heights landslide, Anchorage, Alaska (No. 9). Berkeley (ABD): University of California, Department of Civil Engineering, Institute of Transportation and Traffice Engineering. 
Seed, H. B. and Idriss, I. (1982). Ground motions and soil liquefaction during earthquakes: engineering monographs on earthquake criteria, structural design, and strong motion records. Oakland (ABD): Earthquake Engineering Research Institute.

Seed, H. B. Igancio, A., Alberto, G. M., Ascoli, R. G. and Chan, C. K. (1981). Earthquake-1nduced liquefaction near Lake Amatitlan, Guatemala. Journal of Geotechnical and Geoenvironmental Engineering, 107, 501-518.

Senneset, K. and Janbu, N. (1985). Shear strength parameters obtained from static cone penetration tests. Chaney, R. ve Demars, K. (Ed.), Strength Testing of Marine Sediments: Laboratory and Insitu Measurements. West Conshohocken: ASTM International.

Sert, S., Özocak, A. and Bol, E. (2018). Sıvılaşma bölgelerinde sıvılaşmaz üst tabaka kalınlığının iyileştirme gereksinimine etkisi. Academic Perspective Procedia, 1(1), 1301-1312. https://doi.org/10.33793/acperpro.01.01.202

Shibata, T. and Teparaksa, W. (1988). Evaluation of liquefaction potentials of soils using cone penetration tests. Soils and Foundations, 28(2), 49-60.

https://doi.org/10.3208/sandf1972.28.2_49

Sönmez, B., Dağdelenler, G., Özcan, N.T., Ercanoğlu, M. ve Sönmez, H. (2015). Yapay sinir ağ1 kullanılarak CPT tabanlı sıvilaşma değerlendirme abağının geliştirilmesi. Yerbilimleri, 36(2), 45-59.
Stark, T. D. and Olson, S. M. (1995). Liquefaction resistance using cpt and field case histories. Journal of Geotechnical Engineering, 121(12), 856-869. https://doi.org/10.1061/(ASCE)07339410(1995)121:12(856)

Temizel, I., Arslan, M., Yücel, C., Abdioğlu, E. and Ruffet, G. (2016). Geochronology and geochemistry of eocene-aged volcanic rocks around the bafra (samsun, $\mathrm{n}$ turkey) area: constraints for the interaction of lithospheric mantle and crustal melts. Lithos, 258, 92-114. https://doi.org/10.1016/j.lithos.2016.04.023

Towhata, I. (2008). Geotechnical Earthquake Engineering. Heidelberg: Springer Science \& Bussines Media

Turoğlu, H. (2010). Kizılırmak deltası ve yakın çevresinin jeomorfolojik özellikleri ve insan yaşamındaki etkileri. Anadolu Araştırmaları, 19, $1-26$.

Youd, T. L. and Idriss, I. M. (2001). Liquefaction resistance of soils: summary report from the 1996 NCEER and 1998 NCEER/NSF Workshops on Evaluation of Liquefaction Resistance of Soils. Journal of Geotechnical and Geoenvironmental Engineering, 127(4), 297-313. https://doi.org/10.1061/(ASCE)10900241(2001)127:4(297)

Youd, T. L., Harp, E. L., Keefer, D. K. and Wilson, R.C. (1985). The borah peak, 1daho earthquake of October 28, 1983Liquefaction. Earthquake Spectra, 2(1), 71-89. 